\title{
The SARS-CoV-2 cytopathic effect is blocked with autophagy modulators
}

Kirill Gorshkov ${ }^{1}$, Catherine Z. Chen ${ }^{1}$, Robert Bostwick ${ }^{2}$, Lynn Rasmussen ${ }^{2}$, Miao Xu ${ }^{1}$, Manisha Pradhan ${ }^{1}$, Bruce Nguyen Tran ${ }^{1}$, Wei Zhu ${ }^{1}$, Khalida Shamim ${ }^{1}$, Wenwei Huang ${ }^{1}$, Xin $\mathrm{Hu}^{1}$, Min Shen ${ }^{1}$, Carleen Klumpp-Thomas ${ }^{1}$, Zina Itkin ${ }^{1}$, Paul Shinn ${ }^{1}$, Anton Simeonov ${ }^{1}$, Sam Michael $^{1}$, Matthew D. Hall ${ }^{1}$, Donald C. Lo ${ }^{1}$, Wei Zheng ${ }^{1 *}$

\section{Affiliations:}

${ }^{1}$ National Center for Advancing Translational Sciences, 9800 Medical Center Drive, Rockville, MD, 20850.

${ }^{2}$ Southern Research Institute, 2000 Ninth Avenue South, Birmingham, Alabama, 35205.

*Correspondence:

Kirill Gorshkov - kirill.gorshkov@nih.gov

Wei Zheng -wzheng@mail.nih.gov 


\begin{abstract}
:
SARS-CoV-2 is a new type of coronavirus capable of rapid transmission and causing severe clinical symptoms; much of which has unknown biological etiology. It has prompted researchers to rapidly mobilize their efforts towards identifying and developing anti-viral therapeutics and vaccines. Discovering and understanding the virus' pathways of infection, host-protein interactions, and cytopathic effects will greatly aid in the design of new therapeutics to treat COVID-19. While it is known that chloroquine and hydroxychloroquine, extensively explored as clinical agents for COVID-19, have multiple cellular effects including inhibiting autophagy, there are also dose-limiting toxicities in patients that make clearly establishing their potential mechanisms-of-action problematic. Therefore, we evaluated a range of other autophagy modulators to identify an alternative autophagy-based drug repurposing opportunity. In this work, we found that 6 of these compounds blocked the cytopathic effect of SARS-CoV-2 in Vero-E6 cells with $\mathrm{EC}_{50}$ values ranging from 2.0 to $13 \mu \mathrm{M}$ and selectivity indices ranging from 1.5 to $>10$-fold. Immunofluorescence staining for LC3B and LysoTracker dye staining assays in several cell lines indicated their potency and efficacy for inhibiting autophagy correlated with the measurements in the SARS-CoV-2 cytopathic effect assay. Our data suggest that autophagy pathways could be targeted to combat SARS-CoV-2 infections and become an important component of drug combination therapies to improve the treatment outcomes for COVID-19.
\end{abstract}

Keywords: SARS-CoV-2, cytopathic effect, autophagy, small molecule inhibitors, coronavirus 


\section{Introduction}

The COVID-19 global viral pandemic caused by SARS-CoV-2 began in late 2019 originating from Wuhan, Hubei Province, China (1). SARS-CoV-2 is a member of the Coronaviridae family of positive single-stranded RNA viruses. As of May 14, 2020, there have been over 4,405,000 infections worldwide and 300,000 deaths (2). While not the deadliest virus in the past century, it is highly infectious (estimated $\mathrm{R}_{0}=5.7$ ) (3). The absolute number of infections and mortality will not be known for several years (4) .

SARS-CoV-2 infection in humans produces a disease called coronavirus disease of 2019, COVID-19 (5) (6). It is related to the 2003 coronavirus outbreak of SARS-CoV, the original SARS. Fortunately, the virus was well-contained and no cases have been reported since 2004 . COVID-19 symptoms range from mild fever, tiredness, and dry cough, to acute respiratory distress syndrome, stroke due to blood clots, cardiac and renal damage, and death (7). While some clinical symptoms are common among patients with severe disease, its epidemiology and the mechanisms of disease pathology are still unclear and need to be further studied.

The research and clinical responses have been unprecedented, and much of the effort is focused on identifying therapeutics, including drug repurposing efforts with the experimental anti-Ebola virus drug remdesivir $(8,9)$ and developing vaccines. Chloroquine $(\mathrm{CQ})$, an older FDA-approved anti-malarial drug, along with its better tolerated analog hydroxychloroquine (HCQ), have been reported to inhibit SARS-CoV-2 infection in vitro and show some promise in patients (10-12). In mice, CQ and HCQ display antiviral effects against human coronavirus strain OC43 (13), human enterovirus EV71 (14), Zika virus (15), and human influenza virus H5N1 (16). CQ was not effective in reducing viral titers in the lungs of mice infected with SARS-CoV, although it did 
induce a reduction in markers of inflammation (17). The efficacy of CQ in animal models of SARS-CoV-2 has not yet been reported. CQ and HCQ have been reported to elicit antiviral activity via a number of mechanisms of action including modulation of autophagy.

Autophagy maintains cellular organelle homeostasis by clearing cellular waste and providing the cell with a supply of energy when nutrients are scarce (18). Autophagy also functions as the first line of defense to cleanse the cell of invading pathogens such as viruses, and plays an important role in mediating the innate immune response (19). The activation of autophagy engulfs virions inside host cells via the formation of autophagosomes that subsequently fuse with acidic lysosomes to form autolysosomes through a $\mathrm{pH}$-dependent mechanism. The autolysosomal contents are then degraded by the lysosomal hydrolases. This entire autophagy cycle is called autophagic flux and plays a key role in processing invading viruses. In Drosophila, for example, NF-kB activation during Zika virus infection leads to elevated levels of Drosophila stimulator of interferon genes and increased autophagy in the brain (20). Unfortunately, some viruses have developed mechanisms to escape autophagy (21), avoid the immune response (22), and hijack the autophagosomes for viral replication $(23,24)$.

Viral hijacking of the endocytic pathway for viral entry and utilization of the autophagic machinery for their replication has been reported $(24,25)$. However, some conflicting data has demonstrated that SARS-CoV replication is independent of autophagic mechanisms (26). Viruses have also evolved strategies for escaping degradation through the inhibition of autophagosome-lysosome fusion and autophagic flux $(27,28)$. Nonetheless, given that autophagy inhibitors may act on multiple points within the viral life cycle, treating infection with lysosomotropic compounds may be a viable strategy for suppressing viral attack, and explain the potential therapeutic benefits of CQ and HCQ that have been reported in COVID-19 (29). 
Autophagy inhibitors including CQ, HCQ, and others with related chemical structures are known to prevent the fusion of autophagosomes and lysosomes and blocks the later stages of autophagic flux (30). CQ, in addition to its inhibitory effects on autophagy, has been reported to have broad antiviral effects through several mechanisms of action. One in particular is the disruption of the early steps in the viral life cycle including the release of the virus from the endosome when endocytosis is used for viral entry $(31,32)$. Given the fact that the basic properties of CQ and similar molecules lead to their accumulation in acidic compartments and raise their $\mathrm{pH}$, viruses that depend on low acidic $\mathrm{pH}$ for entry, uncoating, and replication can no longer execute these functions. While they exert multiple cellular effects, their characterized inhibition of autophagic flux and elevation of vesicular $\mathrm{pH}$ is consistent with the antiviral efficacy in vitro (33). Accordingly, a recent SARS-CoV-2 study by Liu et al. has proposed that these drugs may act by preventing the progression of the virions through the endocytic pathway, thereby inhibiting release of the viral genome (12).

In this study, we have identified 6 known autophagy inhibitors that reduce the cytopathic effect (CPE) of SARS-CoV-2 in Vero-E6 cells. We have further investigated the effects of the compounds on markers of autophagy in several different cell lines using LC3B autophagic marker immunostaining as well as LysoTracker dye staining (34). These assays revealed comparable potency of the compounds for inhibiting autophagy compared to inhibition of the virally-induced cytopathic effect. Altogether, we demonstrate that the autophagy inhibitors effectively inhibited SARS-CoV-2 infection in vitro, indicating autophagy as a viable target pathway for COVID-19 drug discovery.

\section{Results}

Autophagy inhibitors block the cytopathic effect of SARS-CoV-2 
We employed a cell-based assay using Vero-E6 host cells that measures the CPE of SARS-CoV-

\section{2 (Fig. 1).}

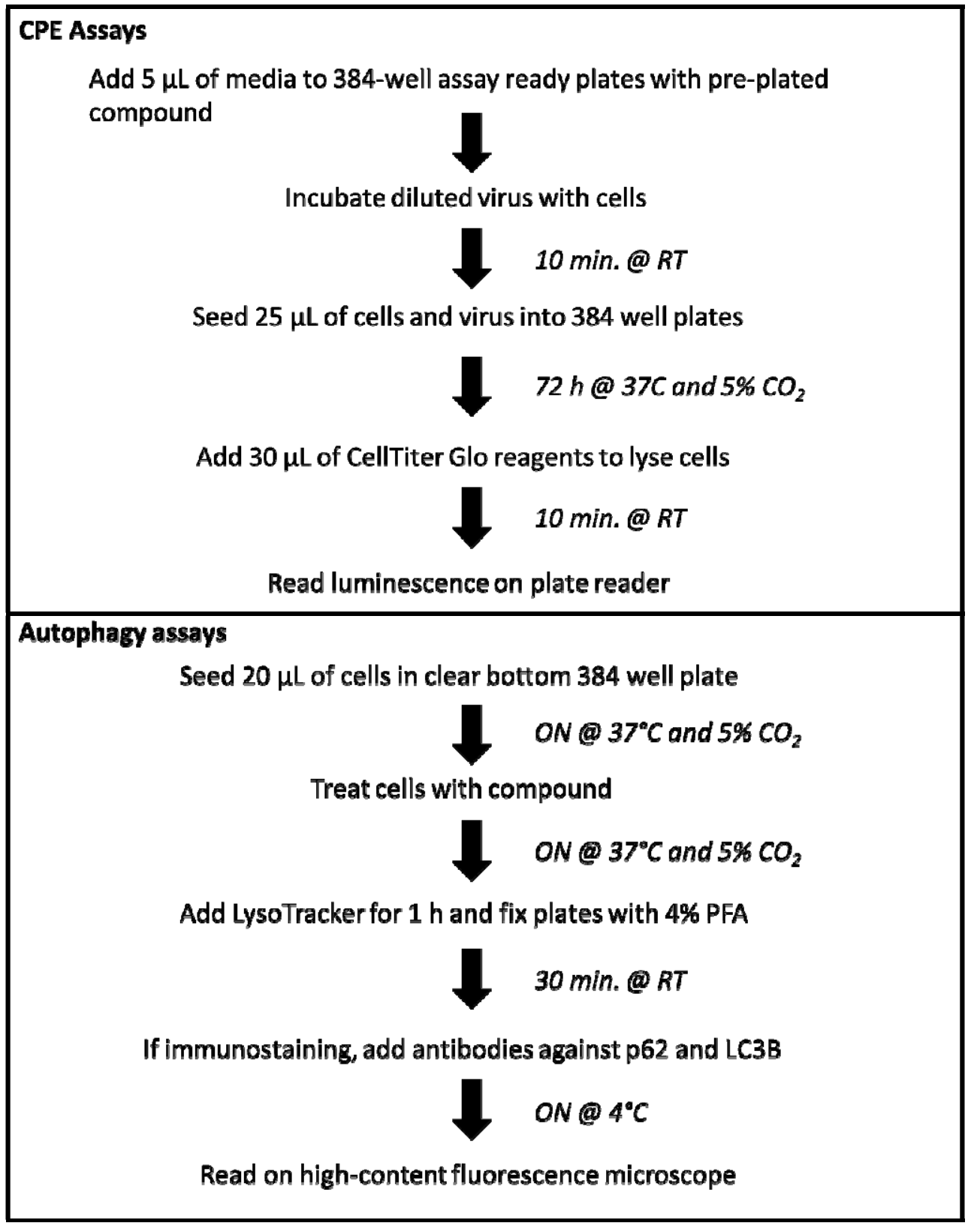

Fig. 1. Workflow overview for CPE assay. Activities and incubation times are shown in a workflow.

The CPE reduction assay is a widely-employed assay format to screen for antiviral agents, and it can be scaled for high-throughput screening $(35,36)$. In this assay, host cell death is a 
consequence of the viral infection and cell viability is a surrogate readout for viral infection that can be measured with a range of cell viability assays. All compounds were tested in doseresponse, and 'hit' antiviral compounds are those that protect the host cells from viral CPE. To increase infectivity of SARS-CoV-2 in the CPE assay, we used a clone of Vero-E6 that had previously been selected for high ACE2 expression (35). The cell viability measurements were normalized to cells not infected with the virus (100\% activity) and untreated cells infected with virus (0\% activity; virus completely kills cells). As a counter-assay, all compounds were tested against cells not exposed to virus, in order to identify compounds that exerted cytotoxicity against Vero E6 cells.

Given that autophagy inhibitors including HCQ have shown efficacy against many different types of viruses (31) including SARS-CoV-2 in CPE assays (12), we assessed the protective effect of a group of autophagy inhibitors including ROC-325, clomipramine, hycanthone, verteporfin, CQ, HCQ, and mefloquine in 384-well plates (Fig. 2). 

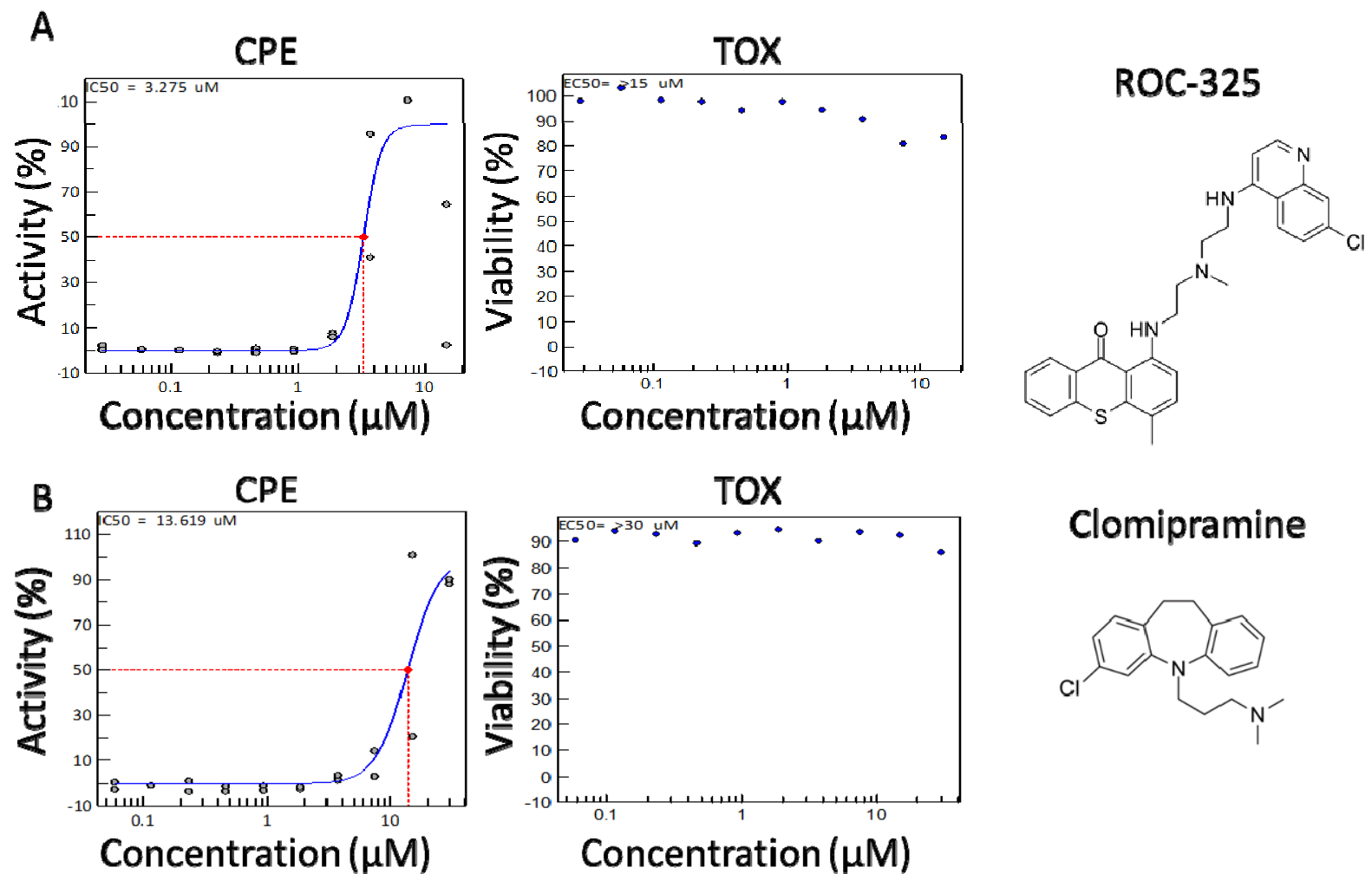

Clomipramine
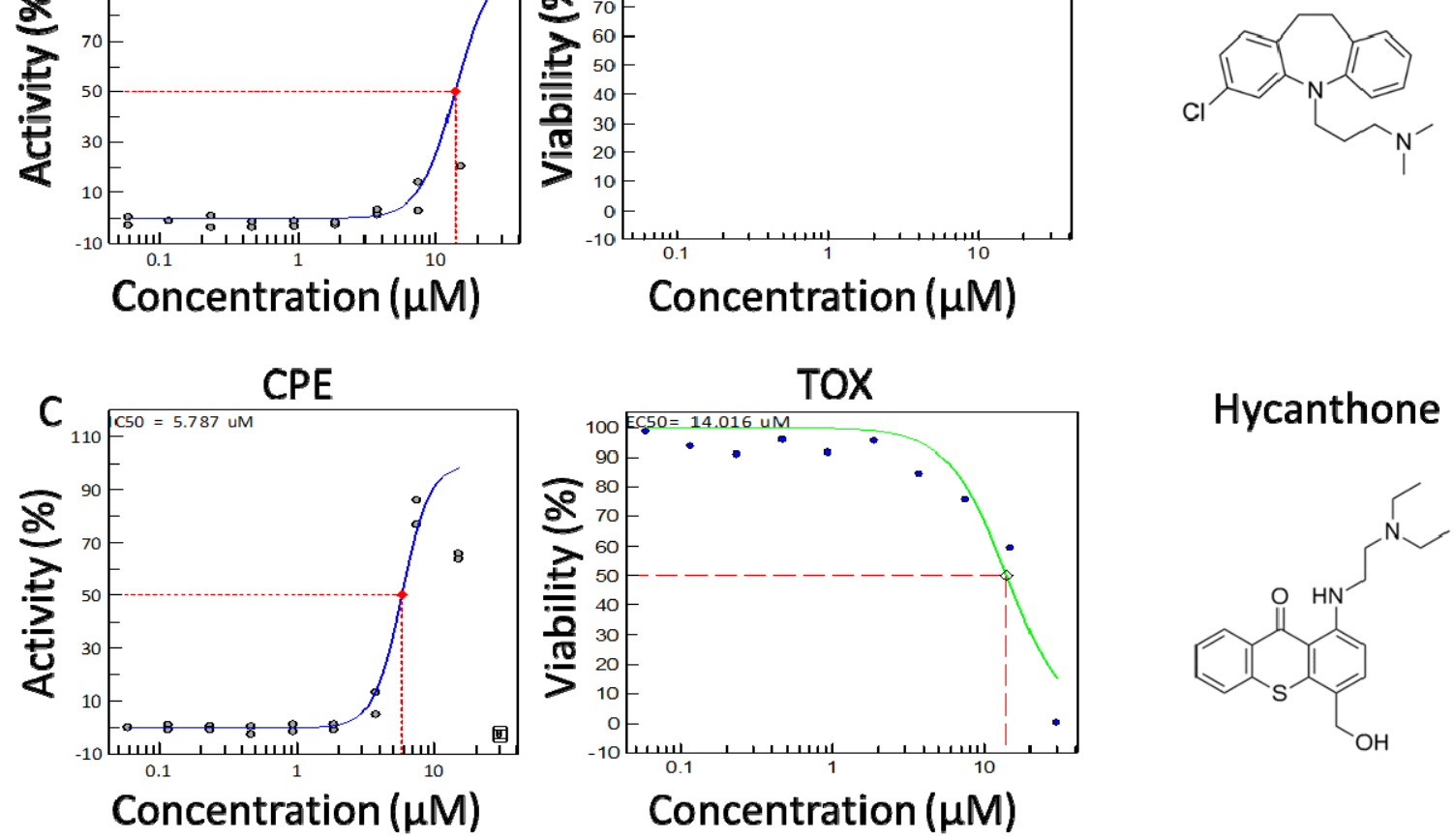

\section{Hycanthone}
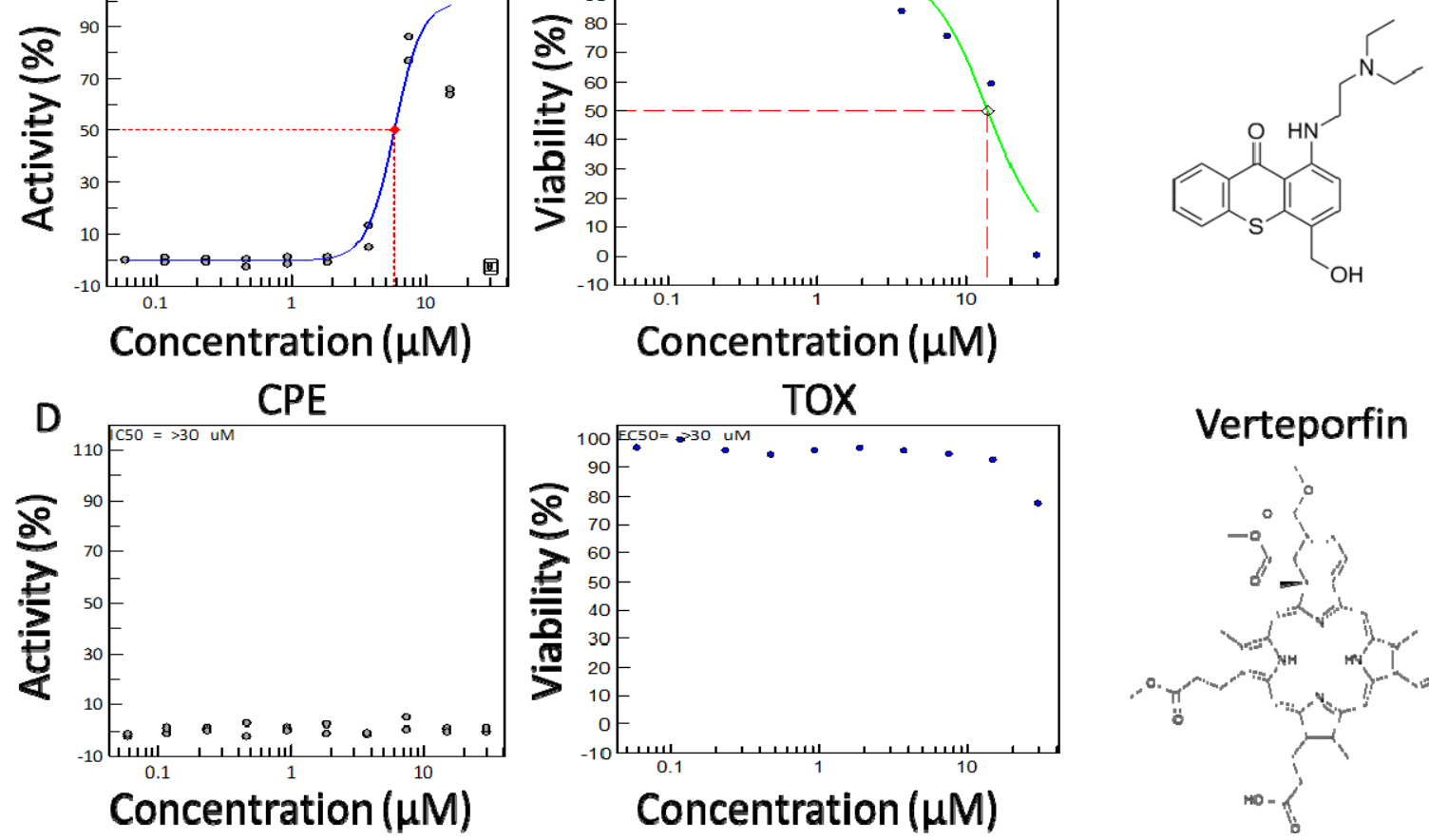

\section{Verteporfin}

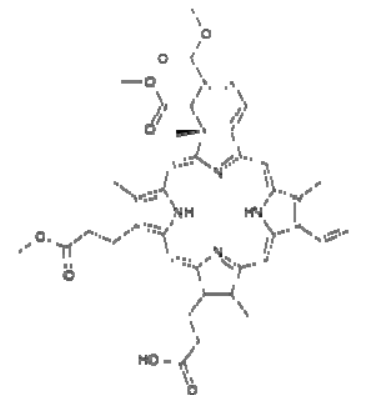

Fig. 2. CPE activity and Toxicity for ROC-325, clomipramine, hycanthone, and verteporfin. (A) ROC-325, (B) clomipramine, (C) hycanthone, and (D) verteporfin CPE activity (blue curve, left 
graph) and Toxicity (green curve, right graph) 10 point, 1:2 dilution concentration-response curves starting at $30.0 \mu \mathrm{M}$ down to $2.29 \mathrm{nM}$, along with their structure. ROC-325 started at 15 $\mu \mathrm{M}$ down to $1.14 \mathrm{nM}$. Red dashed line indicates $\mathrm{EC}_{50}$ or $\mathrm{CC}_{50}$ for $\mathrm{CPE}$ and Toxicity assays, respectively. Duplicate values shown for each concentration. Curves generated using non-linear regression.

While CQ was the most potent compound (discussed below), ROC-325 was the second most potent with an $\mathrm{EC}_{50}$ of $3.28 \mu \mathrm{M}$ and less than $20 \%$ cytotoxicity at $30.0 \mu \mathrm{M}$ (Fig. 2A), indicating a greater than 10-fold selectivity index (SI) between antiviral and cytotoxic concentrations. Clomipramine exhibited an $\mathrm{EC}_{50}$ of $13.6 \mu \mathrm{M}$ while inducing less than $20 \%$ cytotoxicity at 30.0 $\mu \mathrm{M}$ (Fig. 2B). Hycanthone demonstrated an $\mathrm{EC}_{50}$ of $5.79 \mu \mathrm{M}$ and a cytotoxicity $\mathrm{CC}_{50}$ of $14.0 \mu \mathrm{M}$ (Fig. 2C). Hycanthone's concentration-response was bell-shaped due to reduction of cell viability by almost $100 \%$ at $30 \mu \mathrm{M}$. Verteporfin was inactive in the screen against SARS-CoV-2 $\mathrm{CPE}$ and reduced cell viability by approximately $22 \%$ at $30.0 \mu \mathrm{M}$ (Fig. 2D).

The anti-malarial drugs CQ and HCQ inhibited viral CPE with an $\mathrm{EC}_{50}$ of $2.01 \mu \mathrm{M}$ and $4.47 \mu \mathrm{M}$, respectively, with no associated cell toxicity (Fig. 3A,B). HCQ was the third most potent compound tested in the CPE. Mefloquine, a related anti-malarial compound, exhibited an $\mathrm{EC}_{50}$ of $3.85 \mu \mathrm{M}$ with an associated cell toxicity $\mathrm{CC}_{50}$ of $8.78 \mu \mathrm{M}$ and $100 \%$ cytotoxicity at 15.0 to 30.0 $\mu \mathrm{M}$ (Fig. 3C). For comparison, remdesivir, the nucleotide analog inhibitor of RNA-dependent RNA polymerase for a number of viruses and top clinical candidate for SARS-CoV-2 $(8,9,37)$, exhibited an $\mathrm{EC}_{50}$ of $7.04 \mu \mathrm{M}$ with no apparent cytotoxicity (Fig. 3D). The $\mathrm{EC}_{50}$ values for all of the autophagy inhibitor compounds are summarized in Table 1. 

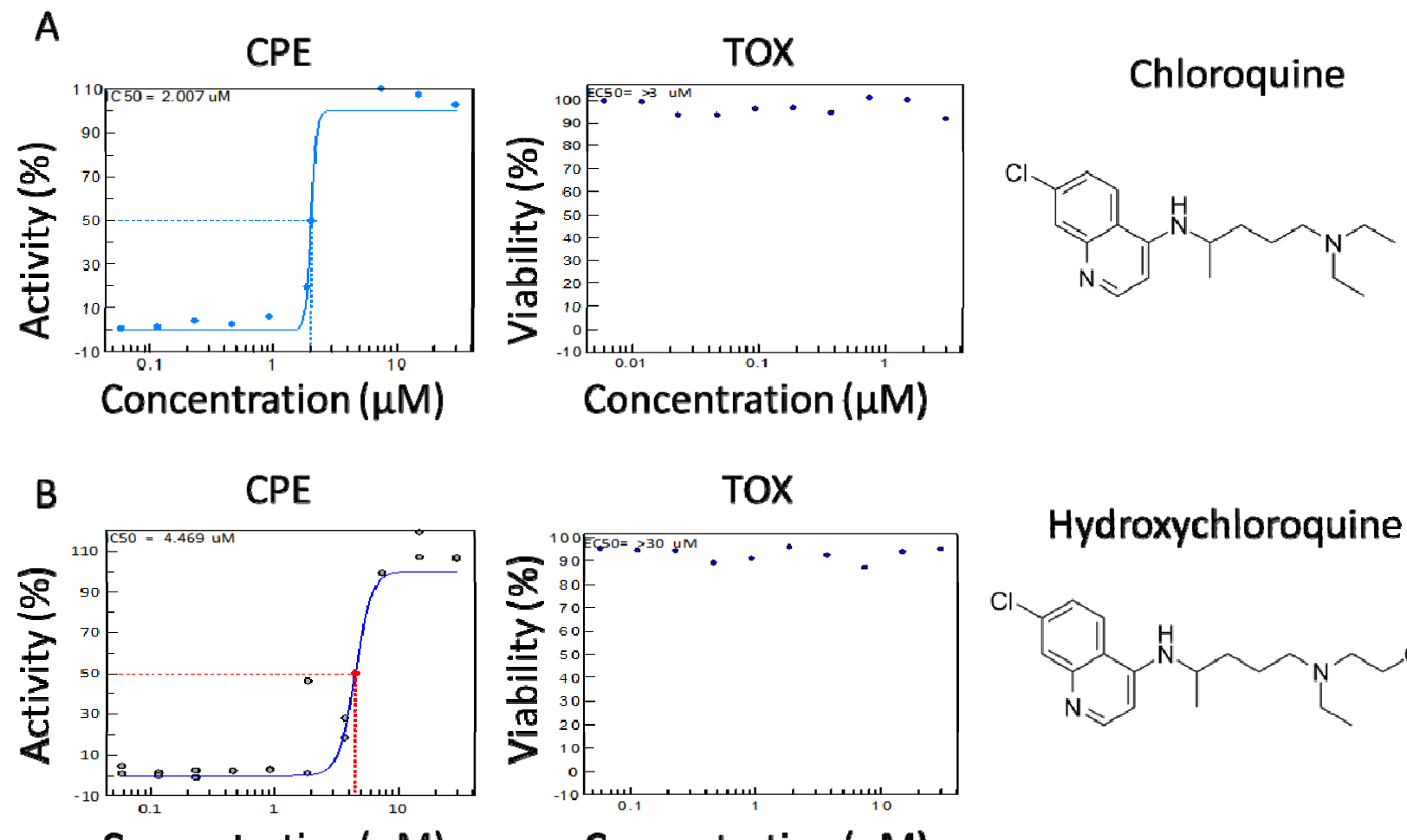

\section{Hydroxychloroquine}<smiles>CCN(CCO)CCCC(C)Nc1ccnc2cc(Cl)ccc12</smiles>

\section{Concentration $(\mu \mathrm{M})$}

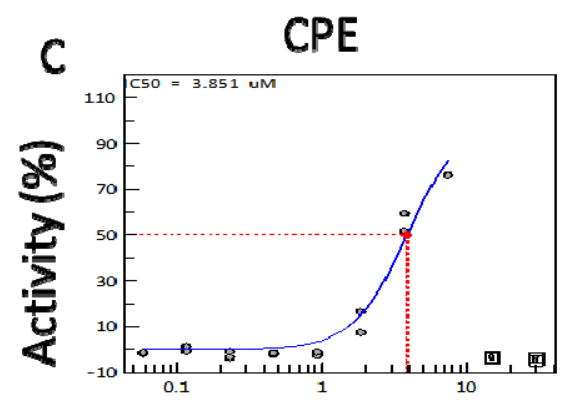

Concentration $(\mu \mathrm{M})$
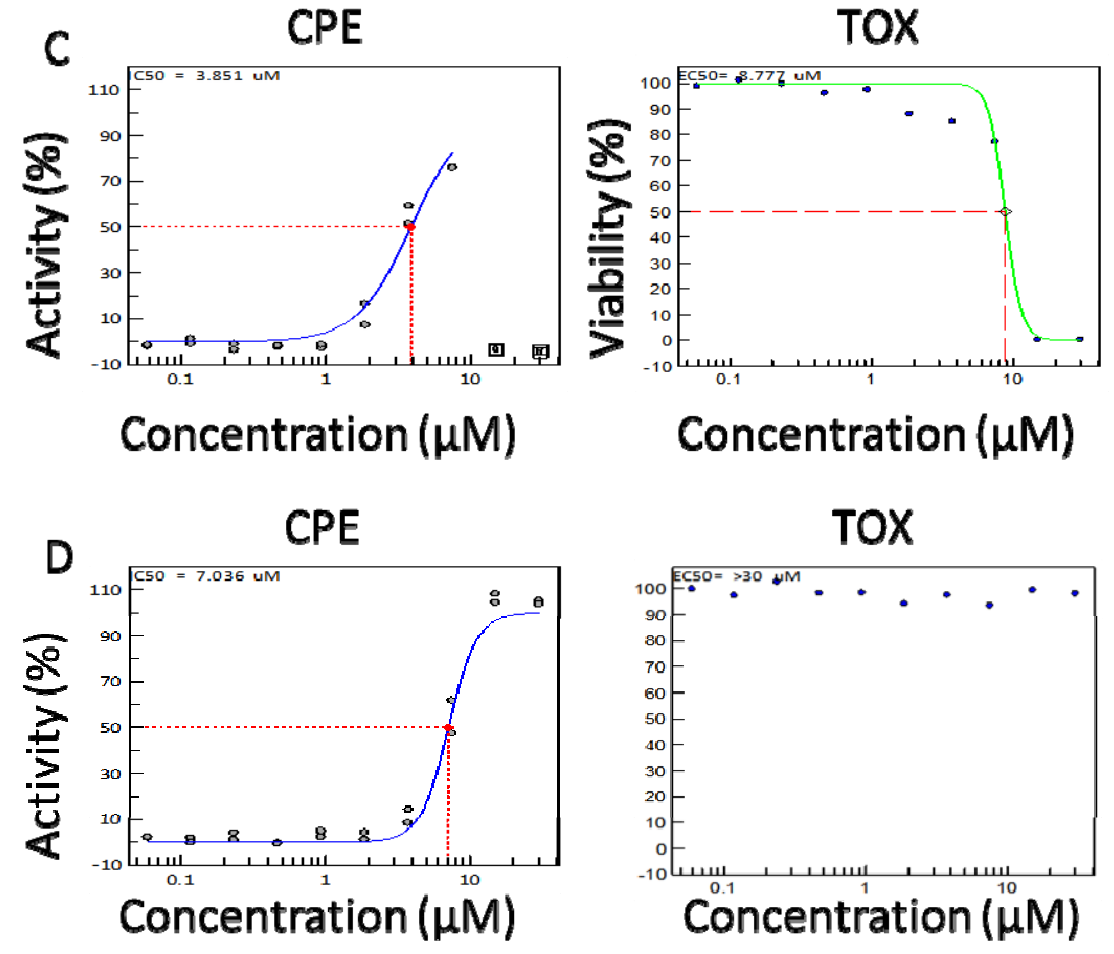

\section{Mefloquine}<smiles>OC(c1cc(C(F)(F)F)nc2c(C(F)(F)F)cccc12)[C@H]1CCCCN1</smiles>

Fig. 3. CPE activity and Toxicity for chloroquine, hydroxychloroquine, and mefloquine. (A)

Chloroquine, (B) hydroxychloroquine, (C) mefloquine, and (D) remdesivir CPE activity (blue 
curve, left graph) and Toxicity (green curve, right graph) 10 point, 1:2 dilution concentrationresponse curves starting at $30.0 \mu \mathrm{M}$ down to $2.29 \mathrm{nM}$, along with theirs structure. Dashed line indicates $\mathrm{EC}_{50}$ or $\mathrm{CC}_{50}$ for $\mathrm{CPE}$ and Toxicity assays, respectively. Duplicate values shown for each concentration. Curves generated using non-linear regression.

\section{Autophagy inhibitors increase LC3B and LysoTracker dye staining}

Because 6 out of the 7 autophagy inhibitors (ROC-325, clomipramine, hycanthone, CQ, HCQ, and mefloquine) showed activity in the CPE assay, we sought to confirm their effect on autophagy in Vero-E6, HeLa, HEK293T, and Huh-7.5 cells using immunostaining for autophagy marker LC3B, as well as LysoTracker dye staining. LC3B immunostaining directly visualizes autophagosomes, while LysoTracker Dye stains acidic organelles. These assays allow for the visualization of autophagosome accumulation and acidic organelles such as endosomes and lysosomes, respectively. Compounds that block autophagic flux are expected to increase LC3B and LysoTracker staining measurements (34). 


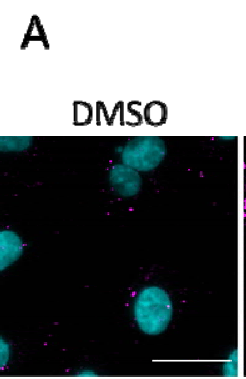

Hoechst 33342

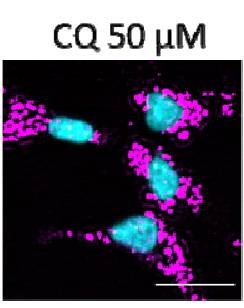

Rabbit anti-LC3B

B

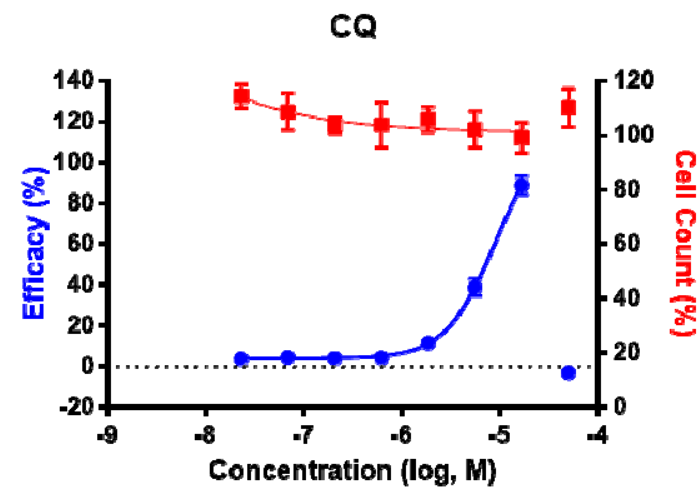

HCQ

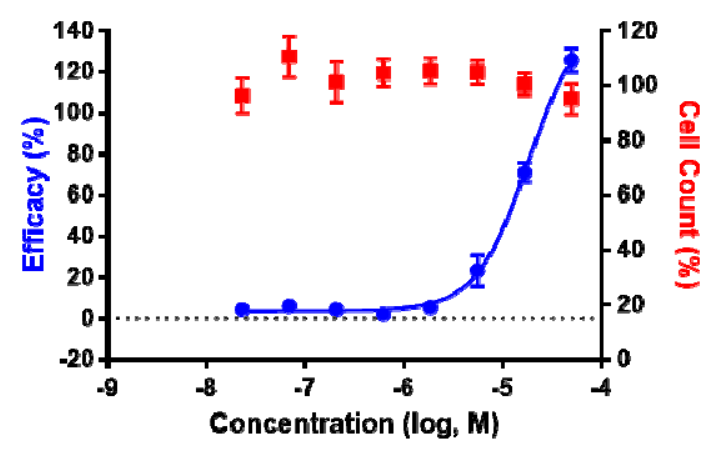

Clomipramine

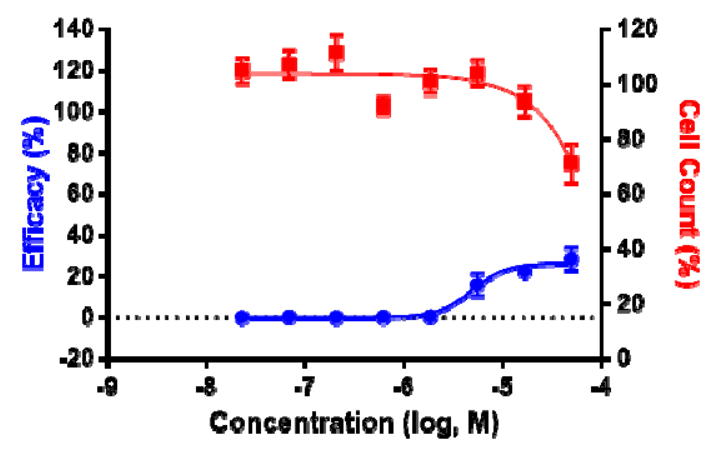

Clomipramine Mefloquine ROC-325 Hycanthone

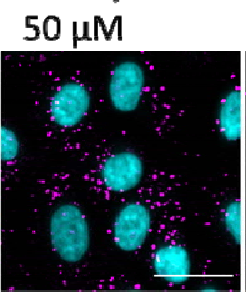

$12 \mu \mathrm{M}$

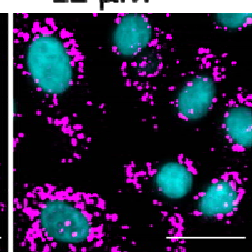

$50 \mu \mathrm{M}$

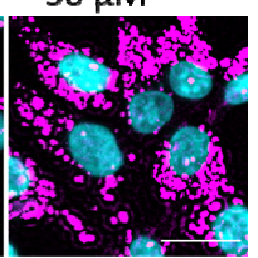

Scale bar, $25 \mu \mathrm{m}$

Mefloquine

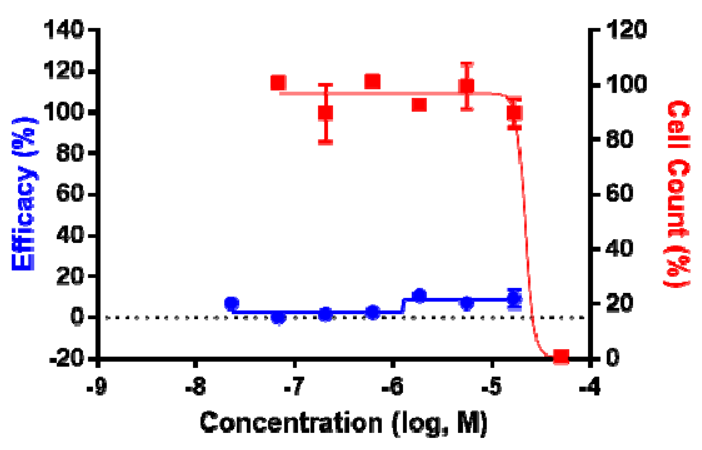

ROC-325

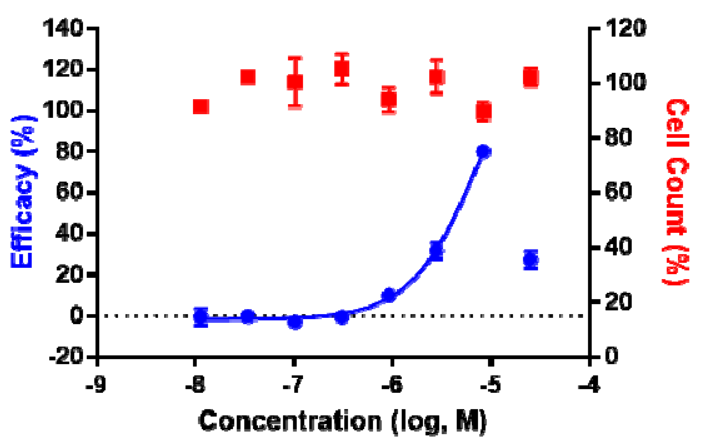

Hycanthone

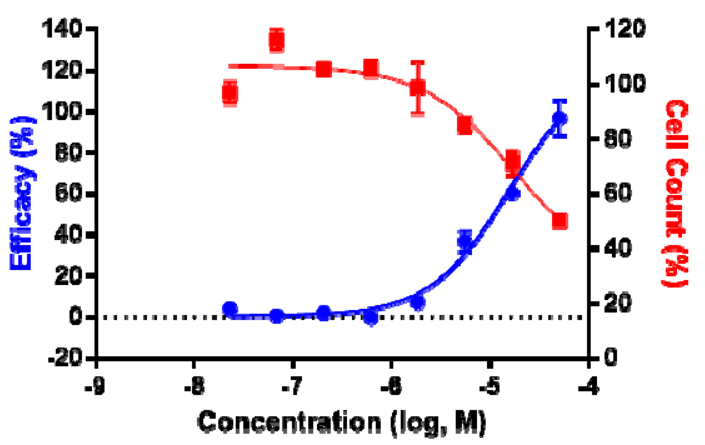


Fig. 4. Autophagy inhibition assay using LC3B immunostaining in Vero-E6 cells. (A) Image montage of DMSO, CQ, HCQ, clomipramine, mefloquine, ROC-325, and hycanthone stained with Hoechst 33342 (cyan) and LC3B (magenta). CQ and HCQ images taken from wells in positive control column 2. Scale bar, $25 \mu \mathrm{m}$. (B) 8 point 1:3 dilution concentration-response curves starting at $50 \mu \mathrm{M}$ down to $0.023 \mu \mathrm{M}$ for compounds in A Blue curve indicates Efficacy, red curve indicates Cell Counts. Efficacy data normalized to DMSO (0\%) and CQ (100\%). Cell count data normalized to DMSO (100\%) and 0 (no cells $0 \%$ ). Error bars indicate SD. N = 3 intraplate replicates. Curves generated using non-linear regression.

To carry out this assay, cells were allowed to adhere overnight, and were then treated with compounds at concentrations ranging from $50 \mu \mathrm{M}-0.02 \mu \mathrm{M}$ for approximately $16 \mathrm{~h}$. In VeroE6 cells, increases in intracellular LC3B spot, also called spots, were concentration-dependent for all of the compounds except for mefloquine (Fig. 4A,B). CQ, HCQ, and hycanthone treatment produced maximal spot counts, while ROC-325 and clomipramine produced a submaximal increase of $80 \%$ and $40 \%$, respectively. Mefloquine was ineffective at inducing LC3B spot accumulation. Increases in LC3B spots indicate an accumulation of LC3B that is localized to the autophagosome when autophagic flux is blocked. The potent effect of CQ and HCQ on LC3B spot counts was apparent in all cell lines tested (Fig. 4 and Fig. S1,3,5). Based on nuclei counts, CQ, HCQ, clomipramine, and ROC-325 were not cytotoxic at the highest concentrations $(50 \mu \mathrm{M}$ for all except for ROC-325 at $25 \mu \mathrm{M})$. In line with the drug toxicity data from the CPE assay, mefloquine was completely toxic at $50 \mu \mathrm{M}$, while hycanthone killed approximately $60 \%$ of cells at $50 \mu \mathrm{M}$. The compound $\mathrm{CC}_{50}$ data was consistent between the two assays. 
In Vero-E6 cells, after drug treatment large concentration-dependent increases of LysoTracker relative spot intensity measurements were observed (Fig. 5A,B). With the exception of HCQ, the maximum efficacy was higher than the CQ positive control (100\%) that was used to normalize the responses. Interestingly, clomipramine and mefloquine, which did not induce large increases in Vero-E6 LC3B spot counts, produced dramatic elevations in LysoTracker relative spot intensity similar to ROC-325 and hycanthone (Fig. 5B). In further support of the CPE assay data, mefloquine was toxic at the highest concentration. 


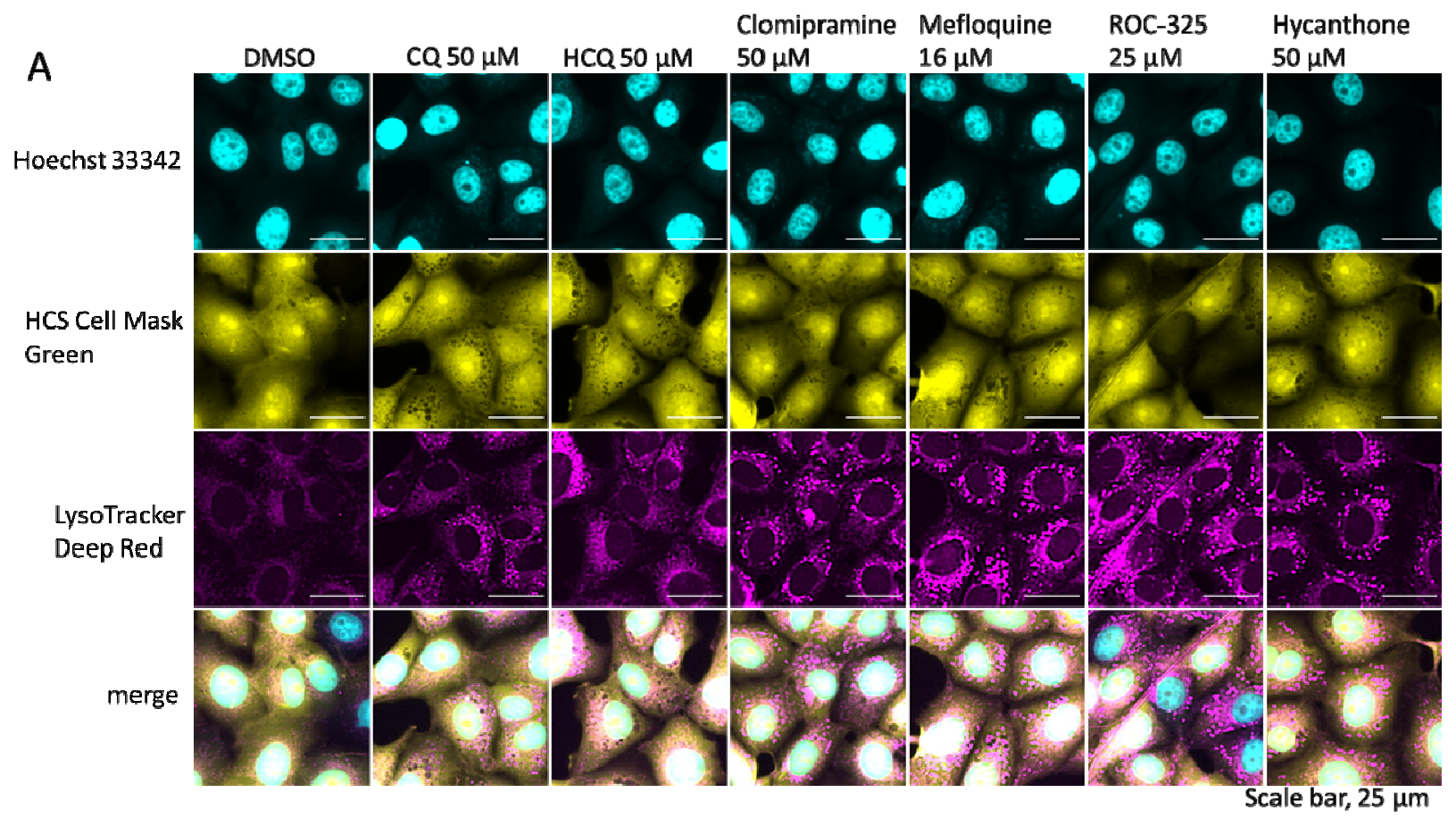

B
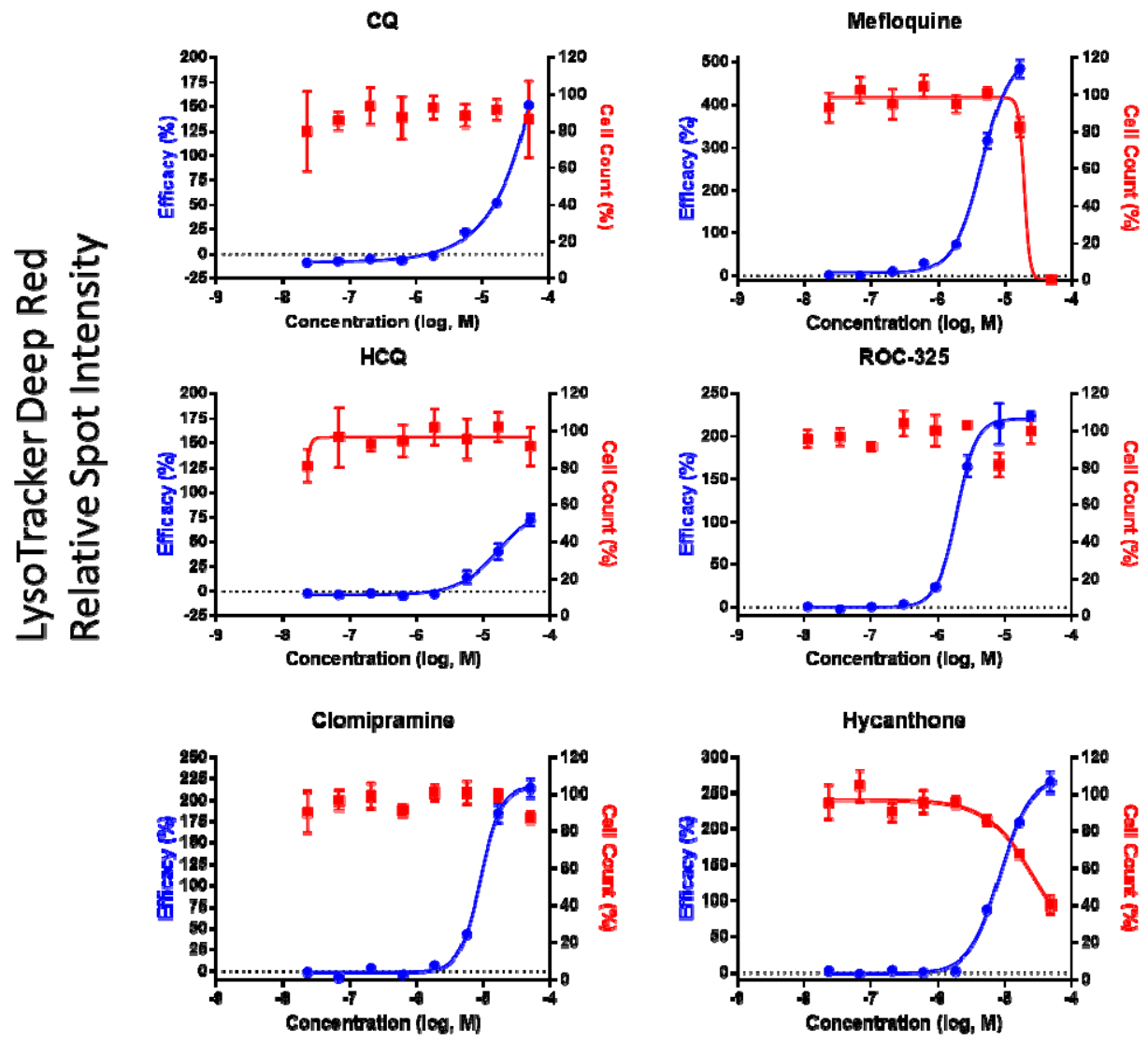
Fig 5. Autophagy inhibition assay using LysoTracker Deep Red staining in Vero-E6 cells. (A) Image montage of DMSO, CQ, HCQ, clomipramine, mefloquine, ROC-325, and hycanthone stained with Hoechst 33342 (cyan), HCS Cell Mask Green (yellow), and LysoTracker Deep Red (magenta). CQ and HCQ images taken from wells in positive control column 2. Scale bar, 25

$\mu \mathrm{m}$. (B) 8 point 1:3 dilution concentration-response curves starting at $50 \mu \mathrm{M}$ down to $0.023 \mu \mathrm{M}$ for compounds in A. Blue curve indicates Efficacy, red curve indicates Cell Counts. Efficacy data normalized to DMSO (0\%) and CQ (100\%). Cell count data normalized to DMSO (100\%) and 0 (no cells $0 \%$ ). Error bars indicate SD. $\mathrm{N}=3$ intra-plate replicates. Curves generated using non-linear regression.

In addition to Vero-E6 cells, we also examined the effects of these compounds in three human cell lines and observed some differences between them (Fig. S1-6). For example, in Huh-7.5, mefloquine increased LC3B spot counts even at low concentrations (Fig. S3), whereas in other cell lines it was not a potent inducer of autophagosome accumulation. Clomipramine was effective in increasing LC3B in all cell lines except for Vero-E6 (Fig. 4, Fig. S1,3,5). In contrast, hycanthone and mefloquine produced the strongest effect on LysoTracker measurements in Vero-E6 compared to the other three cell lines (Fig. 5, Fig. S2,4,6). Although there were some interesting variations in compound effects among the cell lines tested, the average $\mathrm{EC}_{50}$ and $\mathrm{CC}_{50}$ values from the LC3B spot count measurements in all four cell lines corresponded well with the data from the CPE assay, indicating that the effects of the compounds on markers related to autophagy and protection from viral-induced cell death were well-correlated (Table 1). We have illustrated our working hypothesis in Figure 6 as to one potential mechanism for the reduction of viral infection and subsequent CPE. First, in a healthy cell there is normal 
endocytosis of extracellular material and cellular components at the plasma membrane (Fig. 6A).

When healthy cells are treated with autophagy inhibitors, the processes of endolysosome and autolysosome fusion are disrupted, leading to an increase in autophagosomes and late endosomes (Fig. 6B). In the case of an infected cell, potential endocytosis of SARS-CoV-2 leads to the release of viral RNA into the cell, whereas autophagic machinery may be hijacked to prevent flux (orange X) (Fig. 6C). We hypothesize that when autophagy inhibitors are present during viral infection, interference of multiple processes (red Xs) might lead to containment of the virus, and reduction in viral replication (Fig. 6D).
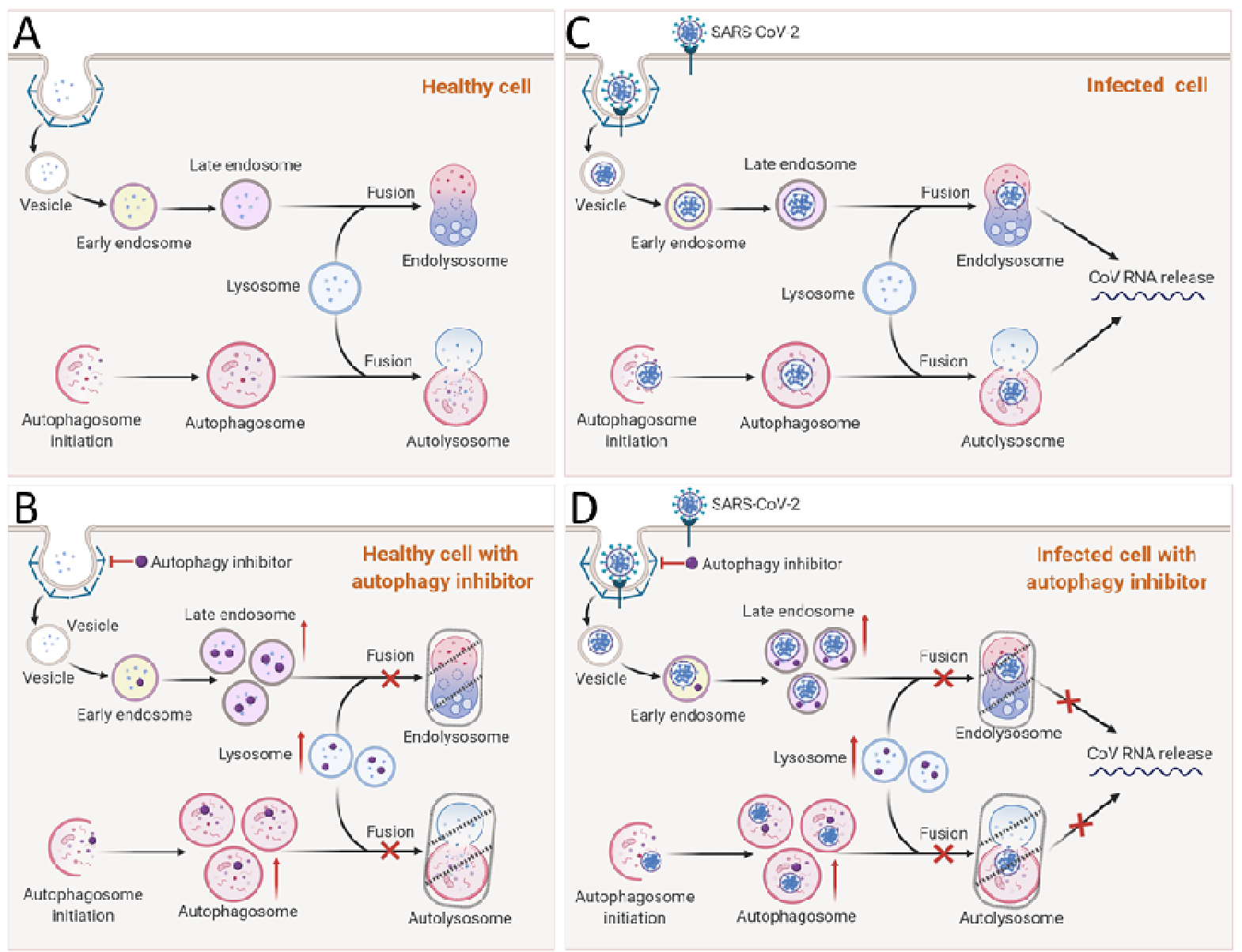

Fig. 6. Illustration of autophagy inhibitors and their blockade of viral infection. (A) Healthy cells have normal autophagic flux and the endocytic pathway is functional. (B) Autophagy inhibitor 
treatment in healthy cells causes a blockade of normal fusion processes and a buildup of endosomes and autophagosomes. (C) In healthy cells, viral infection through endocytosis leads to the release of viral RNA after endosome lysosome fusion. Similarly, autophagy of viral particles may result in formation of viral autophagosomes but lysosome fusion would be blocked by the virus (orange X). Dotted arrow indicates a possible, but unverified event of viral RNA release from autophagosomes. (D) Autophagy inhibitors can block steps (red Xs) within the viral life cycle including at the early steps of endocytosis, the fusion of endosomes with the lysosome, to prevent the release of viral RNA and subsequent cell death.

\section{Discussion}

New anti-viral drug repurposing opportunities are necessary for pre-clinical and clinical evaluation for treating COVID-19. In this work we have identified several autophagy inhibitors that can protect against CPE of SARS-CoV-2 in Vero-E6 cells. ROC-325 (38-40) and clomipramine $(41,42)$ display autophagy inhibitor activity that can completely prevent SARSCoV-2 CPE without any significant inherent cytotoxicity. Hycanthone, an FDA-approved schistosomicide and oxidative metabolite of lucanthone (43-45), and mefloquine (46-48) both showed moderate levels of activity against SARS-CoV-2 CPE, but did exhibit drug-induced cell toxicity at the highest drug concentration tested (up to $30 \mu \mathrm{M}$ ). The autophagy inhibitor verteporfin, a benzoporphyrin derivative used in the clinic as a photosensitizer (49), did not inhibit CPE of SARS-CoV-2, and was not tested in follow-up autophagy assays. To confirm whether CPE protecting compounds interrupted cellular autophagy and lysosomal function, we examined their effects on autophagy marker LC3B (50), along with late endosome and lysosomes as visualized with LysoTracker dye. We found that the activities of autophagy 
inhibition as measured by LC3B spot counts correlated well with inhibition of SARS-CoV-2 measured in the CPE assay for ROC-325, clomipramine, hycanthone, and mefloquine. To our knowledge, this is the first report showing that ROC-325 and hycanthone are efficacious against SARS-CoV-2.

The $72 \mathrm{~h}$ SARS-CoV-2 CPE assay measures the phenotypic consequence of viral infection and replication in cells (51-53). SARS-CoV-2 can induce cell death (54-57) after 48 to $72 \mathrm{~h}$ of infection, and thus cell viability is a surrogate measure of viral replication in vitro. However, there are limitations to the CPE assay including its dependence on the host response and the fact that it is an indirect measurement of SARS-CoV-2 infection and replication. The phenotypic outcome can also vary depending on culture conditions and viral multiplicity of infection (MOI), number of virions that are added per cell during infection (58). The potencies of drug protection against virally-induced cell death can be lower than in other assays that directly measure viral load. Nevertheless, this study confirms that SARS-CoV-2 infection in Vero-E6 cells results in cell death similar to other reports, and that CPE can be suppressed by blocking autophagy with small molecule inhibitors to the same extent as positive control remdesivir $(59,60)$. Recently, a drug-repurposing screen of FDA-approved compounds, using a similar CPE assay with SARSCoV-2 in Vero-E6 cells, found clomipramine $\left(\mathrm{IC}_{50} 5.93 \mu \mathrm{M} ; \mathrm{CC}_{50}>30 \mu \mathrm{M}\right)$ and mefloquine $\left(\mathrm{IC}_{50} 7.11 \mu \mathrm{M} ; \mathrm{CC}_{50}>18.5 \mu \mathrm{M}\right)$ to be active with low toxicity (61). The same study found HCQ to be more active than $\mathrm{CQ}$ with an $\mathrm{IC}_{50}$ of $9.21 \mu \mathrm{M}$ and $42.03 \mu \mathrm{M}$, respectively. Mefloquine was also found to be active in another SARS-CoV-2 CPE screen using Caco-2 cells with an $\mathrm{IC}_{50}$ of 14.1 $\mu \mathrm{M}$ (62). In our study, the SI was calculated using the ratio of the $\mathrm{EC}_{50}$, the half-maximal effective concentration, and the $\mathrm{CC}_{50}$, the half-maximal cytotoxic concentration. Between the $\mathrm{CPE}$ and the autophagy assays there was good correspondence in the cytotoxicity measurements 
by CellTiter-Glo and nuclei counts, respectively. The SI is an important measure for future preclinical development, as it provides insights into the potential clinical safety of a compound at a cellular level. From this work, we show that CQ, HCQ, clomipramine, and ROC-325 were less than $50 \%$ cytotoxic at all concentrations, whereas mefloquine and hycanthone were cytotoxic at the highest concentrations with mefloquine being the most cytotoxic.

Evolution has endowed many viruses with the ability to escape autophagic degradation by using the autophagosome membrane for the formation of viral double membrane vesicles (DMVs), although the precise mechanism is still unclear. It has also been reported that some coronavirus proteins such as open reading frame protein $8 b(\mathrm{ORF}-8 \mathrm{~b})$, directly contribute to cell death following viral infection (63). Interestingly, ORF-8b causes the induction of autophagosome formation accompanied by damaging effects on lysosomal function and autophagy flux. ORF-8b also forms aggregates in cells that caused ER stress and lysosome malfunction, which could be responsible for reduced clearance of viral particles by autophagic flux (63). The nonstructural protein 6 (NSP-6) of the infectious bronchitis virus (IBV), an avian coronavirus, significantly increased the number of autophagosomes in host cells (28). The SARS-CoV accessory protein ORF-3a has three transmembrane domains that insert into the lysosomal membrane causing lysosome function dysregulation and necrotic cell death (27). Recently, Benvenuto and colleagues analyzed 351 available SARS-CoV-2 gene sequences and discussed that the mutations in NSP-6 may modify the virus' activity for inducing autophagy, though experimental data was not presented (21). It appears paradoxical that viral infection inhibits autophagic clearance while autophagy inhibitors, also known to block autophagosome to lysosome fusion, suppress viral infection. Our data, combined with the reported mechanism of action for CQ as an antiviral, suggest that these autophagy inhibitors may interrupt the early steps in the viral life 
cycle, namely the fusion of the viral endosomes with the lysosome, thereby reducing viral replication and protecting cells from viral induced cell death. The effect of altering endosomal $\mathrm{pH}$ among other mechanisms appears to make compounds like HCQ and CQ highly effective against SARS-CoV-2 and other viruses (64). However, more work is needed to elucidate the exact mechanism of action for these autophagy inhibitors in relation to SARS-CoV-2 and the impact at the different stages of the viral life cycle. Other host targets for viral inhibition include the point of entry with clathrin-mediated endocytosis of the virus (65), p38 MAPK involved in viral replication (66), post-translational processing of viral proteins in the Golgi apparatus (67), and budding of the virus from the infected cell $(68,69)$.

ROC-325 was originally developed as an orally available inhibitor of autophagy designed to incorporate the chemical motifs of HCQ and lucanthone, with the goal of both improved autophagic inhibition and consequent single-agent anticancer activity $(39,45)$. ROC-325 is a preclinical candidate with low in vitro and in vivo toxicity and strong anti-cancer properties (40, 70). Our study shows that it may also be a candidate for repositioning as a treatment for COVID19. Clomipramine, a centrally acting, FDA-approved, tricyclic antidepressant used for the treatment of obsessive-compulsive disorder, panic disorder, major depressive disorder, and chronic pain $(71,72)$ may also be an interesting preclinical candidate with its existing regulatory status easing a path towards use in the clinic, although the human Cmax does not cover the CPE $\mathrm{EC}_{50}$. Because most of these compound $\mathrm{EC}_{50}$ values were higher than their human plasma concentrations at the clinically efficacious doses, they likely will not be efficacious as single agents for the treatment of COVID-19 (Table 2). Indeed, toxicity with CQ and HCQ has been reported and caution has to be taken with its clinical application because of potential cardiotoxicity (73). Furthermore, a large observational trial did not find a reduction in death of 
patients taking HCQ, which suggests that large randomized clinical trials are needed to assess the true benefit to patients with regard to decreased mortality rate and duration of hospitalization (74). However, the sum of this work indicates that targeting steps of the viral life cycle in cells with molecules similar to CQ, focusing on their anti-autophagic properties, could be a valid drug discovery strategy for combating SARS-CoV-2. The compounds described here also have value as research tools to better understand the interplay between host autophagy pathway and viral live cycle.

Because such compounds target host cells to suppress SARS-CoV-2 CPE, they have potential to be combined with other drugs that directly target viral proteins for treatment. This type of combination therapy has certain advantages including synergistic activity from different mechanisms of action and reducing the development of viral drug resistance due to the involvement of a host cell target. Furthermore, individual drug concentrations can be lowered in combination therapies to prevent the toxicity seen at higher doses when treating with a single drug. Further tests of the drug combination therapy using SARS-CoV-2 animal models will be needed to confirm the therapeutic usage of these compounds.

Declaration of interests: The authors report no conflict of interest.

Funding: This research was also supported in part by the Intramural Research Program of the National Center for Advancing Translational Sciences, NIH.

Data and materials availability: Data is available upon request.

Table 1. CPE assay in Vero-E6 and average LC3B-based autophagy assay parameters from four cell lines

\begin{tabular}{|lllllllll|}
\hline Compound & MoA & $\begin{array}{l}\text { CPE } \\
\mathbf{E C}_{\mathbf{5 0}} \\
(\boldsymbol{\mu M})\end{array}$ & $\begin{array}{l}\mathbf{C P E} \\
\mathbf{C C}_{\mathbf{5 0}} \\
(\boldsymbol{\mu M})\end{array}$ & $\begin{array}{l}\mathbf{C P E} \\
\text { SI }\end{array}$ & $\begin{array}{l}\text { Autophagy } \\
\mathbf{E C}_{\mathbf{5 0}}(\boldsymbol{\mu M})\end{array}$ & $\begin{array}{l}\text { Autophagy } \\
\mathbf{C C}_{\mathbf{5 0}}(\boldsymbol{\mu M})\end{array}$ & $\begin{array}{l}\text { Autophagy } \\
\text { SI }\end{array}$ & $\begin{array}{l}\text { MoA } \\
\text { Ref. }\end{array}$ \\
\hline Chloroquine & $\downarrow$ lysosome fusion & 2.01 & $>30$ & $>10$ & $3.29 \pm 1.86$ & $>50$ & $>10$ & $(30)$ \\
\hline ROC-325 & $\downarrow$ lysosome fusion & 3.28 & $>30$ & $>10$ & $5.2 \pm 1.71$ & $>25$ & $>10$ & $(38)$ \\
\hline
\end{tabular}




\begin{tabular}{|c|c|c|c|c|c|c|c|c|}
\hline Mefloquine & $\downarrow$ autophagic flux & 3.85 & 8.78 & 2.3 & $7.3^{*}$ & $18.4 \pm 2.08$ & 2.6 & $(46)$ \\
\hline $\begin{array}{l}\text { Hydroxy- } \\
\text { chloroquine }\end{array}$ & $\downarrow$ lysosome fusion & 4.47 & $>30$ & $>10$ & $6.55 \pm 6.67$ & $>50$ & $>10$ & (12) \\
\hline Hycanthone & $\begin{array}{l}\uparrow \text { lysosomal } \\
\text { membrane } \\
\text { permeabilization }\end{array}$ & 5.79 & 14.2 & 2.5 & $7.35 \pm 4.7$ & $\begin{array}{l}11.3 \pm \\
2.73 \dagger\end{array}$ & 1.5 & (45) \\
\hline Clomipramine & $\downarrow$ autophagic flux & 13.6 & $>30$ & $>10$ & $13.2 \pm 5.4$ & $>50$ & $>10$ & $(42)$ \\
\hline Verteporfin & $\begin{array}{l}\downarrow \text { autophagosome } \\
\text { formation }\end{array}$ & ND & $>30$ & ND & ND & ND & ND & (75) \\
\hline
\end{tabular}

* Could only be calculated from Huh-7.5

$\dagger$ Max inhibition of cell viability $\sim 60 \%$

ND - not determined

SI> 10 used when no $\mathrm{CC}_{50}$ was calculated

Table 2. Clinical features of autophagy inhibitor compounds

\begin{tabular}{|c|c|c|c|c|c|}
\hline Compound & $\begin{array}{l}\text { Primary } \\
\text { indication }\end{array}$ & $\begin{array}{l}\text { Regulatory } \\
\text { Status }\end{array}$ & Cmax & Pharmacological characteristics & Reference \\
\hline ROC-325 & $\begin{array}{l}\text { Autophagy } \\
\text { inhibitor for } \\
\text { cancer }\end{array}$ & $\begin{array}{l}\text { Preclinical } \\
\text { development }\end{array}$ & ND & $\begin{array}{l}\text { Highly bioavailable in vivo, effective } \\
\text { again renal cell carcinoma, well } \\
\text { tolerated in vivo }\end{array}$ & $(39,40)$ \\
\hline Clomipramine & $\begin{array}{l}\text { Serotonin } \\
\text { reuptake } \\
\text { inhibitor for } \\
\text { OCD }\end{array}$ & FDA-approved & $\begin{array}{l}0.29 \\
\mu \mathrm{M}\end{array}$ & $\begin{array}{l}\text { Well-absorbed, metabolized to } \\
\text { desmethylclomipramine, high Vd, } \\
\mathrm{T}_{1 / 2}=24 \mathrm{~h}\end{array}$ & $(76)$ \\
\hline Hycanthone & $\begin{array}{l}\text { Anti- } \\
\text { helminthic }\end{array}$ & FDA-approved & ND & $\begin{array}{l}\text { Active metabolite of lucanthone, } \mathrm{T}_{1 / 2} \\
=3 \text { - } 5 \mathrm{~h} \text {, well-absorbed in monkey, } \\
\text { human data lacking }\end{array}$ & $(77)$ \\
\hline Chloroquine & $\begin{array}{l}\text { Anti- } \\
\text { malarial }\end{array}$ & FDA-approved & $\begin{array}{l}0.17- \\
0.32 \\
\mu \mathrm{M}\end{array}$ & $\begin{array}{l}\text { Slow elimination, } \mathrm{T}_{1 / 2}=30-60 \\
\text { days, } 75 \% \text { bioavailable, } \mathrm{Vd}=100 \\
\mathrm{~L} / \mathrm{kg}, 50-70 \% \text { plasma bound, } \\
\text { accumulates in blood cells }\end{array}$ & $(78,79)$ \\
\hline $\begin{array}{l}\text { Hydroxychloro } \\
\text { quine }\end{array}$ & $\begin{array}{l}\text { Anti- } \\
\text { malarial }\end{array}$ & FDA-approved & $\begin{array}{l}1.5 \\
\mu \mathrm{M}\end{array}$ & $\begin{array}{l}\text { Similar to CQ, rapid and complete } \\
\text { absorption, } \mathrm{T}_{1 / 2} \text { around } 40 \mathrm{~d}\end{array}$ & $(80)$ \\
\hline Mefloquine & $\begin{array}{l}\text { Anti- } \\
\text { malarial }\end{array}$ & FDA-approved & $\begin{array}{l}4.5 \\
\mu \mathrm{M}\end{array}$ & $\begin{array}{l}\text { High Cmax can cause toxicity, slow } \\
\text { elimination like CQ and HCQ }\end{array}$ & $(81)$ \\
\hline
\end{tabular}

\section{Materials and Methods}

\section{Study Design}

Sample Size and Replicates:

For the CPE, inter-plate duplicates were used for each data point for quantitative HTS and curve fitting. For CPE luminescence measurements, each well was read once. For the autophagy assay, three intra-plate replicates were used in consecutive columns for quantitative HTS, high-content analysis, and curve fitting. For the autophagy assay automated high-content imaging, each well 
was imaged 6 times in equally spaced fields using a 40x objective. This allowed for the collection of data from approximately 500 or more cells per well.

Data inclusion and outliers:

All data was included in the CPE assay. For the high-content imaging autophagy assays, efficacy data points were excluded in the case where there was $>80 \%$ cell death. For non-linear curve fitting, data points were excluded when there was an experimental error that prevented proper drug addition or staining.

\section{Selection of endpoints:}

CPE assay $72 \mathrm{~h}$ and autophagy assay 16-18 h endpoints were selected $a$ priori based on previous studies.

\section{Research Objectives:}

We aimed to contribute valuable pharmacological data towards the fight against COVID-19 by screening autophagy inhibitor compounds in a viral cytopathic effect assay to determine their potency and efficacy in preventing virally-induced cell death. We further aimed to validate these autophagy inhibitors in a number of cell lines to understand whether the pharmacological effect of autophagy inhibition corresponded with anti-viral effects. Autophagy inhibition is a known anti-viral strategy effective in vitro, in vivo, and potentially in human patients. However, there is a lack of clinically available autophagy inhibitors due to dose-limiting adverse side effects. After screening, we identified a new preclinical compound ROC-325 is a potential target for further development. 
Units of investigation:

Traditional cell culture methods were used in high-throughput formats for CPE and autophagy screening. Vero-E6 cells previously developed by collaborators were used for the CPE assay. Vero-E6, HEK293T, and HeLa cells were purchased from ATCC, and Huh-7.5 cells were a gift from the Tang Lab at FSU.

\section{Experimental design:}

The experiments put forth in this research article were controlled laboratory experiments devised with the guidelines established for high-throughput screening. Cells were maintained in a healthy state with proper cell culture techniques and treated using small volumes of compound dissolved in DMSO. Luminescence readings were collected for the CPE assay and fluorescence images were captured using automated high-content microscopy. Controls were assigned to specific wells and compounds were distributed throughout the entire 384 well plates. For the autophagy assays, compound dilutions were arranged vertically with the highest concentration in the middle of the plate and the lowest concentrations on the edges. Each compound was in three consecutive columns. Further details are provided in the Methods section. Measurements for the CPE assay and fluorescence images were captured sequentially well by well. For the autophagy assay, a horizontal serpentine imaging sequence was used.

\section{Blinding:}

For the luminescence readings, the simple data structure was processed according to the plate layout annotation. For the autophagy assay, a custom high-content imaging protocol was developed in Columbus Analyzer for each cell line based on the detection of signals from the 
controls and the processing was automated. The data was initially processed using compound identifiers called NCGC values, and then the data was quantified and visualized in Excel and Prism GraphPad. The compound NCGC numbers were then unmasked using the corresponding compound names.

\section{Reagents}

The following items were purchased from Gibco: MEM (11095), DMEM (11965092), HI FBS (14000), Pen/Strep (15140). TrypLE (12604013), PBS -/- (w/o $\mathrm{Ca}^{2+}$ or $\left.\mathrm{Mg}^{2+}\right)$ (10010049), Trypsin-EDTA (25300-054). Hyclone FBS (SH30071.03) was purchased from GE Healthcare.

The following items were purchased from ATCC: EMEM (30-2003), Vero-E6 (CRL-1586, RRID:CVCL_0574), HeLa (CCL-2, RRID:CVCL_0030), HEK293T (CRL-3216, RRID:CVCL_0063 ). Huh-7.5 cells were a gift from the Tang Lab at FSU. The following items were purchased from Invitrogen: Live Cell Imaging Buffer (A14291DJ), LysoTracker Deep Red (L12492), goat-anti-mouse AlexaFluor-647 (A-21242, RRID:AB_2535811), HCS Cell Mask

Green (H32714), Hoechst 33342 (H3570). LC3B primary rabbit antibody (3868S, RRID:AB_2137707) was purchased from Cell Signaling Technologies. Cell Staining Buffer (420201) was purchased from BioLegend. The following items were purchased from Corning: 384-well plates (3764 BC), BioCoat 384-well poly-d-Lysine coated plates (354663 BC), Amphotericin B (30-003-CF). 100\% Methanol (34860) was purchased from Sigma-Aldrich. Calpain Inhibitor IV (208724) was purchased from CalbioChem.

\section{Cell Culture}

Vero-E6 cells previously selected for high ACE2 expression (82) were cultured in MEM/10\% HI FBS supplemented with $0.5 \mu \mathrm{g} / \mathrm{mL}$ amphotericin B and passaged twice per week at 1:5 dilutions using trypsin. Briefly, cell culture media was aspirated, and cells were washed twice with PBS. 2 
$\mathrm{mL}$ of trypsin is added for 1-2 minutes at room temperature and $10 \mathrm{~mL}$ of EMEM is added to wash flask and create a single cell suspension. Cells are spun at 800 RPM for 5 minutes. Supernatant was aspirated and cells resuspended in fresh media for seeding into flasks or multiwell plates.

Vero-E6 (grown in EMEM, 10\% FBS, and 1\% Penicillin/Streptomycin), HeLa CCL-2, HEK293T and Huh-7.5 (grown in DMEM, 10\% FBS, and 1\% Penicillin/Streptomycin) were cultured in T175 flasks and passaged at 95\% confluency. Briefly, cells were washed once with PBS and dissociated from the flask using TrypLE. Cells were counted prior to seeding.

\section{Preparation of Assay Ready Plates}

An $80 \mu \mathrm{L}$ aliquot of each compound stock solution (10 mM in 100\% DMSO) is transferred into empty wells in columns 3 and 13 of an Echo® Qualified 384-Well Polypropylene Source Microplate (Labcyte P-05525). Compounds are diluted 2-fold by transferring $40 \mu \mathrm{L}$ of each sample into $40 \mu \mathrm{L}$ DMSO in the adjacent well (columns 4 and 14) and mixing. This process is repeated to create 8 more 2-fold serially diluted samples in the wells of columns 5-12 and 6-22. Using a Labcyte ECHO 550 (San Jose, CA) acoustic liquid handling system a $90 \mathrm{~nL}$ aliquot of each diluted sample is dispensed into corresponding wells of a Corning 3764BC plate. An equal volume of DMSO is added to control wells to maintain $0.3 \%$ DMSO final assay concentration in all wells. These are referred to as Assay Ready Plates (ARPs) and are stored at $-20^{\circ} \mathrm{C}$.

\section{Method for measuring antiviral effect of compounds}

A CPE assay previously used to measure antiviral effects against SARS-CoV (35) was adapted for performance in 384 well plates to measure CPE of SARS CoV-2 with the following modifications. Cells harvested and suspended at 160,000 cells/ml in MEM/1\% PSG/1\% HEPES supplemented 2\% HI FBS were batch inoculated with SARS CoV-2 (USA_WA1/2020) at 
M.O.I. of approximately 0.002 which resulted in approximately $5 \%$ cell viability $72 \mathrm{~h}$ post infection. ARPs were brought to room temperature and $5 \mu 1$ of assay media was dispensed to all wells. The plates were transported into the BSL-3 facility were a $25 \mu \mathrm{L}$ aliquot of virus inoculated cells (4000 Vero E6 cells/well) was added to each well in columns 3-24. The wells in columns 23-24 contained virus infected cells only (no compound treatment). A $25 \mu \mathrm{L}$ aliquot of uninfected cells was added to columns 1-2 of each plate for the cell only (no virus) controls. After incubating plates at $37^{\circ} \mathrm{C}$ with $5 \% \mathrm{CO}_{2}$ and $90 \%$ humidity for $72 \mathrm{~h}, 30 \mu \mathrm{L}$ of Cell TiterGlo (Promega, Madison, WI) was added to each well. Following incubation at room temperature for 10 minutes the plates were sealed with a clear cover and surface decontaminated and luminescence was read using a Perkin Elmer Envision (Waltham, MA) plate reader to measure cell viability. Raw data from each test well was normalized to the average signal of non-infected cells (Avg. Cells; 100\% inhibition) and virus infected cells only (Avg. Virus; 0\% inhibition) to calculate \% inhibition of CPE using the following formula: \% inhibition CPE $=100 *($ Test Cmpd - Avg. Virus)/(Avg. Cells - Avg. Virus).

\section{Method for measuring cytotoxic effect of compounds}

Compound cytotoxicity was assessed in a BSL-2 counter screen as follows: Host cells in media were added in $25 \mu \mathrm{l}$ aliquots (4000 cells/well) to each well of assay ready plates prepared with test compounds as above. Cells only (100\% viability) and cells treated with hyamine at $100 \mu \mathrm{M}$ final concentration ( $0 \%$ viability) serve as the high and low signal controls, respectively, for cytotoxic effect in the assay. DMSO was maintained at a constant concentration for all wells $(0.3 \%)$ as dictated by the dilution factor of stock test compound concentrations. After incubating plates at $37^{\circ} \mathrm{C} / 5 \% \mathrm{CO}_{2}$ and $90 \%$ humidity for $72 \mathrm{~h}$, plates were brought to room temperature and 30 $\mu$ l Cell Titer-Glo (Promega) was added to each well. Luminescence was read using a BMG 
PHERAstar plate reader following incubation at room temperature for 10 minutes to measure cell viability.

Autophagy assays

$20 \mu \mathrm{L}$ of cells were seeded into 384-well, black, clear-bottom, poly-d-lysine coated plates to achieve $60 \%$ confluent wells. Plates were covered with metal lids and placed in a $37^{\circ} \mathrm{C}$ incubator with $95 \%$ humidity and 5\% CO2 overnight before compound treatment. $100 \mathrm{~nL}$ of compound per well was dispensed using the Labcyte Echo 655. The compounds were added at 8 concentrations with 1:3 dilutions starting at $50 \mu \mathrm{M}$ down to $0.02 \mu \mathrm{M}$. ROC-325 was dispensed at the highest working concentration of $25 \mu \mathrm{M}$ due to a maximum solubility of $5 \mathrm{mM}$ in DMSO.

For LysoTracker staining, $5 \mu \mathrm{L}$ of a 5x $250 \mathrm{nM}$ LysoTracker Deep Red (Invitrogen, Carlsbad, CA) diluted in Live Cell Imaging Buffer (Invitrogen) was added to the plates mentioned above and incubated for $1 \mathrm{~h}$ at $37^{\circ} \mathrm{C}$ with $5 \% \mathrm{CO}_{2}$ after which cells were fixed using $4 \% \mathrm{PFA}$ (Electron Microscopy Sciences, Hatfield, PA) and incubated at room temperature for 30 minutes. Media in wells was then evacuated and cells were washed three times with PBS using the automated Bluewasher plate washing system from Blue Cat Bio (Concord, MA). Plates were then sealed and imaged on the IN Cell 2500 HS (GE Healthcare, Chicago, IL) automated high-content imaging system. Images was uploaded to Columbus Analyzer and processed for high-content analysis.

For LC3B immunostaining, media was evacuated on the Bluewasher and $100 \%$ ice-cold methanol was added to wells for 10 minutes at $-30^{\circ} \mathrm{C}$. Plates were washed three times with PBS and blocked with Cell Staining Buffer (BioLegend, San Diego, CA). Plates were then incubated with rabbit-anti-LC3B (Cell Signaling Technologies, Danvers, MA) antibodies in Cell Staining Buffer for $2 \mathrm{~h}$ at room temperature. Plates were washed three times with PBS and secondary 
antibody goat-anti-mouse AlexaFluor-647 (Invitrogen) were added in Cell Staining Buffer for 1 h. Plates were washed three times in PBS before adding 1:5000 Hoechst 33342 (Invitrogen). After a final three washes in PBS, plates were sealed and imaged on the IN Cell $2500 \mathrm{HS}$ automated high-content imaging system. Images was uploaded to Columbus Analyzer and processed for high-content analysis. Image montages were prepared using Fiji (ImageJ, NIH).

\section{Statistical analysis}

CPE assay raw data from each test well was normalized to the average signal of non-infected cells (Avg. Cells; 100\% inhibition) and virus infected cells only (Avg. Virus; 0\% inhibition) to calculate \% inhibition of CPE using the following formula: \% inhibition CPE $=100 *($ Test Cmpd - Avg Virus)/(Avg Cells - Avg Virus). EC 50 values were obtained using non-linear regression. High-content image analysis data was downloaded as a Microsoft Excel spreadsheet. DMSO negative control (0\% activity) (col. 1 and 24 for acoustic dispensing) and CQ positive control (100\% activity) (col. 2 for acoustic dispensing, 8 wells) was used to normalize each compound concentrations' response. The other 8 wells of column 2 contained $10 \mathrm{mM} \mathrm{HCQ}$. EC $\mathrm{F}_{50}$ values were obtained using non-linear regression in Graphpad Prism 7.04. In some cases, the highest concentration point was not included in curve-fit due to technical issues during experimental execution, although the measured value was shown. When cell viability was below $20 \%$, the efficacy point was excluded altogether (i.e. mefloquine at $24 \mu \mathrm{M}$ or $8 \mu \mathrm{M}$ ). Six fields per well were imaged on the IN Cell 2500HS. LC3B and LysoTracker data was obtained using a single well with hundreds of cells for each compound concentration from three intra-plate replicate wells were imaged when acoustic dispensing was used for compound treatment. Cell counts were also reported using nuclear object segmentation. GraphPad Prism 7.04v was used for visualizing 
autophagy data. $\mathrm{EC}_{50}$ and $\mathrm{CC}_{50}$ values from high-content imaging were obtained using non-linear regression.

\section{References:}

1. X. Yang, Y. Yu, J. Xu, H. Shu, H. Liu, Y. Wu, L. Zhang, Z. Yu, M. Fang, T. Yu, Clinical course and outcomes of critically ill patients with SARS-CoV-2 pneumonia in Wuhan, China: a single-centered, retrospective, observational study. The Lancet Respiratory Medicine, (2020).

2. E. Dong, H. Du, L. Gardner, An interactive web-based dashboard to track COVID-19 in real time. The Lancet infectious diseases, (2020).

3. S. Sanche, Y. T. Lin, C. Xu, E. Romero-Severson, N. Hengartner, R. Ke, Early Release-High Contagiousness and Rapid Spread of Severe Acute Respiratory Syndrome Coronavirus 2.

4. E. Callaway, D. Cyranoski, S. Mallapaty, E. Stoye, J. Tollefson, The coronavirus pandemic in five powerful charts. Nature 579, 482-483 (2020).

5. H. A. Rothan, S. N. Byrareddy, The epidemiology and pathogenesis of coronavirus disease (COVID-19) outbreak. Journal of autoimmunity, 102433 (2020).

6. W. H. Organization.

7. Z. Xu, L. Shi, Y. Wang, J. Zhang, L. Huang, C. Zhang, S. Liu, P. Zhao, H. Liu, L. Zhu, Pathological findings of COVID-19 associated with acute respiratory distress syndrome. The Lancet respiratory medicine 8, 420-422 (2020).

8. W.-C. Ko, J.-M. Rolain, N.-Y. Lee, P.-L. Chen, C.-T. Huang, P.-I. Lee, P.-R. Hsueh, Arguments in favour of remdesivir for treating SARS-CoV-2 infections. International journal of antimicrobial agents $\mathbf{5 5}$, 105933-105933 (2020).

9. J. Grein, N. Ohmagari, D. Shin, G. Diaz, E. Asperges, A. Castagna, T. Feldt, G. Green, M. L. Green, F.-X. Lescure, E. Nicastri, R. Oda, K. Yo, E. Quiros-Roldan, A. Studemeister, J. Redinski, S. Ahmed, J. Bernett, D. Chelliah, D. Chen, S. Chihara, S. H. Cohen, J. Cunningham, A. D’ Arminio Monforte, S. Ismail, H. Kato, G. Lapadula, E. L'Her, T. Maeno, S. Majumder, M. Massari, M. Mora-Rillo, Y. Mutoh, D. Nguyen, E. Verweij, A. Zoufaly, A. O. Osinusi, A. DeZure, Y. Zhao, L. Zhong, A. Chokkalingam, E. Elboudwarej, L. Telep, L. Timbs, I. Henne, S. Sellers, H. Cao, S. K. Tan, L. Winterbourne, P. Desai, R. Mera, A. Gaggar, R. P. Myers, D. M. Brainard, R. Childs, T. Flanigan, Compassionate Use of Remdesivir for Patients with Severe Covid-19. New England Journal of Medicine, (2020).

10. P. Gautret, J. C. Lagier, P. Parola, V. T. Hoang, L. Meddeb, M. Mailhe, B. Doudier, J. Courjon, V. Giordanengo, V. E. Vieira, H. T. Dupont, S. Honore, P. Colson, E. Chabriere, B. La Scola, J. M. Rolain, P. Brouqui, D. Raoult, Hydroxychloroquine and azithromycin as a treatment of COVID-19: results of an open-label non-randomized clinical trial. International journal of antimicrobial agents, 105949 (2020).

11. X. Yao, F. Ye, M. Zhang, C. Cui, B. Huang, P. Niu, X. Liu, L. Zhao, E. Dong, C. Song, S. Zhan, R. Lu, H. Li, W. Tan, D. Liu, In Vitro Antiviral Activity and Projection of Optimized Dosing Design of Hydroxychloroquine for the Treatment of Severe Acute Respiratory Syndrome Coronavirus 2 (SARS-CoV2). Clinical Infectious Diseases, (2020).

12. J. Liu, R. Cao, M. Xu, X. Wang, H. Zhang, H. Hu, Y. Li, Z. Hu, W. Zhong, M. Wang, Hydroxychloroquine, a less toxic derivative of chloroquine, is effective in inhibiting SARS-CoV-2 infection in vitro. Cell Discov 6, 16-16 (2020).

13. E. Keyaerts, S. Li, L. Vijgen, E. Rysman, J. Verbeeck, M. Van Ranst, P. Maes, Antiviral activity of chloroquine against human coronavirus OC43 infection in newborn mice. Antimicrobial agents and chemotherapy 53, 3416-3421 (2009).

14. Y. W. Tan, W. K. Yam, J. Sun, J. J. H. Chu, An evaluation of Chloroquine as a broad-acting antiviral against Hand, Foot and Mouth Disease. Antiviral Research 149, 143-149 (2018). 
15. S. A. Shiryaev, P. Mesci, A. Pinto, I. Fernandes, N. Sheets, S. Shresta, C. Farhy, C. T. Huang, A. Y. Strongin, A. R. Muotri, A. V. Terskikh, Repurposing of the anti-malaria drug chloroquine for Zika Virus treatment and prophylaxis. Scientific reports 7, 15771 (2017).

16. Y. Yan, Z. Zou, Y. Sun, X. Li, K.-F. Xu, Y. Wei, N. Jin, C. Jiang, Anti-malaria drug chloroquine is highly effective in treating avian influenza A H5N1 virus infection in an animal model. Cell Research 23, 300-302 (2013).

17. D. L. Barnard, C. W. Day, K. Bailey, M. Heiner, R. Montgomery, L. Lauridsen, P. K. S. Chan, R. W. Sidwell, Evaluation of Immunomodulators, Interferons and Known in Vitro SARS-CoV Inhibitors for Inhibition of SARS-Cov Replication in BALB/c Mice. Antiviral Chemistry and Chemotherapy 17, 275-284 (2006).

18. J. Mao, E. Lin, L. He, J. Yu, P. Tan, Y. Zhou, Autophagy and Viral Infection. Adv Exp Med Biol 1209, 5578 (2019).

19. L. Ahmad, S. Mostowy, V. Sancho-Shimizu, Autophagy-Virus Interplay: From Cell Biology to Human Disease. Frontiers in Cell and Developmental Biology 6, (2018).

20. Y. Liu, B. Gordesky-Gold, M. Leney-Greene, N. L. Weinbren, M. Tudor, S. Cherry, InflammationInduced, STING-Dependent Autophagy Restricts Zika Virus Infection in the Drosophila Brain. Cell host \& microbe 24, 57-68.e53 (2018).

21. D. Benvenuto, S. Angeletti, M. Giovanetti, M. Bianchi, S. Pascarella, R. Cauda, M. Ciccozzi, A. Cassone, Evolutionary analysis of SARS-CoV-2: how mutation of Non-Structural Protein 6 (NSP6) could affect viral autophagy. Journal of Infection, (2020).

22. C.-S. Shi, H.-Y. Qi, C. Boularan, N.-N. Huang, M. Abu-Asab, J. H. Shelhamer, J. H. Kehrl, SARScoronavirus open reading frame-9b suppresses innate immunity by targeting mitochondria and the MAVS/TRAF3/TRAF6 signalosome. J Immunol 193, 3080-3089 (2014).

23. A. Abdoli, M. Alirezaei, P. Mehrbod, F. Forouzanfar, Autophagy: The multi-purpose bridge in viral infections and host cells. Reviews in medical virology 28, e1973 (2018).

24. T. S. Fung, D. X. Liu, The ER stress sensor IRE1 and MAP kinase ERK modulate autophagy induction in cells infected with coronavirus infectious bronchitis virus. Virology 533, 34-44 (2019).

25. K. Knoops, M. Kikkert, S. H. Worm, J. C. Zevenhoven-Dobbe, Y. van der Meer, A. J. Koster, A. M. Mommaas, E. J. Snijder, SARS-coronavirus replication is supported by a reticulovesicular network of modified endoplasmic reticulum. PLoS biology 6, e226 (2008).

26. M. Schneider, K. Ackermann, M. Stuart, C. Wex, U. Protzer, H. M. Schätzl, S. Gilch, Severe acute respiratory syndrome coronavirus replication is severely impaired by MG132 due to proteasomeindependent inhibition of M-calpain. J Virol 86, 10112-10122 (2012).

27. Y. Yue, N. R. Nabar, C.-S. Shi, O. Kamenyeva, X. Xiao, I.-Y. Hwang, M. Wang, J. H. Kehrl, SARSCoronavirus Open Reading Frame-3a drives multimodal necrotic cell death. Cell Death Dis. 2018 (10.1038/s41419-018-0917-y).

28. E. M. Cottam, M. C. Whelband, T. Wileman, Coronavirus NSP6 restricts autophagosome expansion. Autophagy 10, 1426-1441 (2014).

29. N. C. Gassen, D. Niemeyer, D. Muth, V. M. Corman, S. Martinelli, A. Gassen, K. Hafner, J. Papies, K. Mösbauer, A. Zellner, A. S. Zannas, A. Herrmann, F. Holsboer, R. Brack-Werner, M. Boshart, B. MüllerMyhsok, C. Drosten, M. A. Müller, T. Rein, SKP2 attenuates autophagy through Beclin1-ubiquitination and its inhibition reduces MERS-Coronavirus infection. Nat Commun 10, 5770-5770 (2019).

30. M. Mauthe, I. Orhon, C. Rocchi, X. Zhou, M. Luhr, K. J. Hijlkema, R. P. Coppes, N. Engedal, M. Mari, F. Reggiori, Chloroquine inhibits autophagic flux by decreasing autophagosome-lysosome fusion. Autophagy 14, 1435-1455 (2018).

31. A. Savarino, L. Di Trani, I. Donatelli, R. Cauda, A. Cassone, New insights into the antiviral effects of chloroquine. The Lancet Infectious Diseases 6, 67-69 (2006).

32. A. Savarino, J. R. Boelaert, A. Cassone, G. Majori, R. Cauda, Effects of chloroquine on viral infections: an old drug against today's diseases? The Lancet. Infectious diseases 3, $722-727$ (2003).

33. N. Yang, H.-M. Shen, Targeting the Endocytic Pathway and Autophagy Process as a Novel Therapeutic Strategy in COVID-19. Int J Biol Sci 16, 1724-1731 (2020).

34. N. Mizushima, T. Yoshimori, B. Levine, Methods in mammalian autophagy research. Cell 140, 313-326 (2010).

35. W. E. Severson, N. Shindo, M. Sosa, T. Fletcher, 3rd, E. L. White, S. Ananthan, C. B. Jonsson, Development and validation of a high-throughput screen for inhibitors of SARS CoV and its application in screening of a 100,000-compound library. Journal of biomolecular screening 12, 33-40 (2007). 
36. C. B. Maddox, L. Rasmussen, E. L. White, Adapting Cell-Based Assays to the High Throughput Screening Platform: Problems Encountered and Lessons Learned. JALA (Charlottesville, Va.) 13, 168-173 (2008).

37. M. Wang, R. Cao, L. Zhang, X. Yang, J. Liu, M. Xu, Z. Shi, Z. Hu, W. Zhong, G. Xiao, Remdesivir and chloroquine effectively inhibit the recently emerged novel coronavirus (2019-nCoV) in vitro. Cell research 30, 269-271 (2020).

38. J. S. Carew, S. T. Nawrocki, Drain the lysosome: Development of the novel orally available autophagy inhibitor ROC-325. Autophagy 13, 765-766 (2017).

39. T. M. Jones, C. Espitia, W. Wang, S. T. Nawrocki, J. S. Carew, Moving beyond hydroxychloroquine: the novel lysosomal autophagy inhibitor ROC-325 shows significant potential in preclinical studies. Cancer Communications 39, 1-3 (2019).

40. J. S. Carew, C. M. Espitia, W. Zhao, Y. Han, V. Visconte, J. Phillips, S. T. Nawrocki, Disruption of Autophagic Degradation with ROC-325 Antagonizes Renal Cell Carcinoma Pathogenesis. Clinical Cancer Research 23, 2869-2879 (2017).

41. Z. J. Yang, C. E. Chee, S. Huang, F. Sinicrope, Autophagy modulation for cancer therapy. Cancer biology \& therapy 11, 169-176 (2011).

42. M. Rossi, E. R. Munarriz, S. Bartesaghi, M. Milanese, D. Dinsdale, M. A. Guerra-Martin, E. T. Bampton, P. Glynn, G. Bonanno, R. A. Knight, Desmethylclomipramine induces the accumulation of autophagy markers by blocking autophagic flux. Journal of cell science 122, 3330-3339 (2009).

43. D. Rosi, G. Peruzzotti, E. W. Dennis, D. A. Berberian, H. Freele, B. F. Tullar, S. Archer, Hycanthone, a new active metabolite of lucanthone. Journal of medicinal chemistry 10, 867-876 (1967).

44. A. Petcherski, U. Chandrachud, E. S. Butz, M. C. Klein, W.-N. Zhao, S. A. Reis, S. J. Haggarty, M. O. Ruonala, S. L. Cotman, An Autophagy Modifier Screen Identifies Small Molecules Capable of Reducing Autophagosome Accumulation in a Model of CLN3-Mediated Neurodegeneration. Cells 8, 1531 (2019).

45. J. S. Carew, C. M. Espitia, J. A. Esquivel, D. Mahalingam, K. R. Kelly, G. Reddy, F. J. Giles, S. T. Nawrocki, Lucanthone is a novel inhibitor of autophagy that induces cathepsin D-mediated apoptosis. Journal of Biological Chemistry 286, 6602-6613 (2011).

46. N. Sharma, S. Thomas, E. B. Golden, F. M. Hofman, T. C. Chen, N. A. Petasis, A. H. Schönthal, S. G. Louie, Inhibition of autophagy and induction of breast cancer cell death by mefloquine, an antimalarial agent. Cancer letters 326, 143-154 (2012).

47. $\quad$ N. Sharma, Inhibition of Tumor Cell Growth by Mefloquine via Multimechanistic Effects Involving Increased Cellular Stress, Inhibition of Autophagy, and Impairment of Cellular Energy Metabolism. (University of Southern California, 2013).

48. J. H. Shin, S. J. Park, Y. K. Jo, E. S. Kim, H. Kang, J.-H. Park, E. H. Lee, D.-H. Cho, Suppression of autophagy exacerbates Mefloquine-mediated cell death. Neuroscience Letters 515, 162-167 (2012).

49. E. Donohue, A. Thomas, N. Maurer, I. Manisali, M. Zeisser-Labouebe, N. Zisman, H. J. Anderson, S. S. $\mathrm{Ng}, \mathrm{M}$. Webb, M. Bally, The autophagy inhibitor verteporfin moderately enhances the antitumor activity of gemcitabine in a pancreatic ductal adenocarcinoma model. Journal of Cancer 4, 585 (2013).

50. I. Tanida, S. Waguri, Measurement of autophagy in cells and tissues. Methods in molecular biology (Clifton, N.J.) 648, 193-214 (2010).

51. P. C. Familletti, S. Rubinstein, S. Pestka, in Methods in enzymology. (Elsevier, 1981), vol. 78, pp. $387-394$.

52. A. J. Darling, J. A. Boose, J. Spaltro, Virus assay methods: accuracy and validation. Biologicals 26, 105110 (1998).

53. J. W. Noah, W. Severson, D. L. Noah, L. Rasmussen, E. L. White, C. B. Jonsson, A cell-based luminescence assay is effective for high-throughput screening of potential influenza antivirals. Antiviral research 73, 50-59 (2007).

54. P. H. Guzzi, D. Mercatelli, C. Ceraolo, F. M. Giorgi, Master Regulator Analysis of the SARS-CoV2/Human Interactome. Journal of clinical medicine 9, (2020).

55. Y. Xiong, Y. Liu, L. Cao, D. Wang, M. Guo, A. Jiang, D. Guo, W. Hu, J. Yang, Z. Tang, H. Wu, Y. Lin, M. Zhang, Q. Zhang, M. Shi, Y. Liu, Y. Zhou, K. Lan, Y. Chen, Transcriptomic characteristics of bronchoalveolar lavage fluid and peripheral blood mononuclear cells in COVID-19 patients. Emerging microbes \& infections 9, 761-770 (2020).

56. K. L. Siu, K. S. Yuen, C. Castaño-Rodriguez, Z. W. Ye, M. L. Yeung, S. Y. Fung, S. Yuan, C. P. Chan, K. Y. Yuen, L. Enjuanes, D. Y. Jin, Severe acute respiratory syndrome coronavirus ORF3a protein activates the NLRP3 inflammasome by promoting TRAF3-dependent ubiquitination of ASC. FASEB journal : official publication of the Federation of American Societies for Experimental Biology 33, 8865-8877 (2019). 
57. y. chen, Z. Feng, B. Diao, R. Wang, G. Wang, C. Wang, Y. Tan, L. Liu, C. Wang, Y. Liu, Y. Liu, Z. Yuan, L. Ren, Y. Wu, The Novel Severe Acute Respiratory Syndrome Coronavirus 2 (SARS-CoV-2) Directly Decimates Human Spleens and Lymph Nodes. medRxiv, 2020.2003.2027.20045427 (2020).

58. P. Shabram, E. Aguilar-Cordova, Multiplicity of Infection/Multiplicity of Confusion. Molecular Therapy 2, 420-421 (2000).

59. S. Jeon, M. Ko, J. Lee, I. Choi, S. Y. Byun, S. Park, D. Shum, S. Kim, Identification of antiviral drug candidates against SARS-CoV-2 from FDA-approved drugs. bioRxiv, 2020.2003.2020.999730 (2020).

60. F. Touret, M. Gilles, K. Barral, A. Nougairède, E. Decroly, X. de Lamballerie, B. Coutard, <em>In vitro</em> screening of a FDA approved chemical library reveals potential inhibitors of SARS-CoV-2 replication. bioRxiv, 2020.2004.2003.023846 (2020).

61. S. Weston, C. M. Coleman, R. Haupt, J. Logue, K. Matthews, M. Frieman, Broad anti-coronaviral activity of FDA approved drugs against SARS-CoV-2 <em>in vitro</em> and SARS-CoV <em >in vivo</em>. bioRxiv, 2020.2003.2025.008482 (2020).

62. D. B. Bernhard Ellinger, Andrea Zaliani et al., Identification of inhibitors of SARS-CoV-2 in-vitro cellular toxicity in human (Caco-2) cells using a large scale drug repurposing collection. Research Square, (2020).

63. C.-S. Shi, N. R. Nabar, N.-N. Huang, J. H. Kehrl, SARS-Coronavirus Open Reading Frame-8b triggers intracellular stress pathways and activates NLRP3 inflammasomes. Cell Death Discov. 2019 (10.1038/s41420-019-0181-7).

64. M. A. A. Al-Bari, Targeting endosomal acidification by chloroquine analogs as a promising strategy for the treatment of emerging viral diseases. Pharmacol Res Perspect 5, e00293-e00293 (2017).

65. T. Y. Hu, M. Frieman, J. Wolfram, Insights from nanomedicine into chloroquine efficacy against COVID19. Nat Nanotechnol 15, 247-249 (2020).

66. M. Kono, K. Tatsumi, A. M. Imai, K. Saito, T. Kuriyama, H. Shirasawa, Inhibition of human coronavirus 229E infection in human epithelial lung cells (L132) by chloroquine: involvement of p38 MAPK and ERK. Antiviral research 77, 150-152 (2008).

67. C. A. Devaux, J.-M. Rolain, P. Colson, D. Raoult, New insights on the antiviral effects of chloroquine against coronavirus: what to expect for COVID-19? International journal of antimicrobial agents, 105938105938 (2020).

68. M.-L. Ng, S.-H. Tan, E.-E. See, E.-E. Ooi, A.-E. Ling, Proliferative growth of SARS coronavirus in Vero E6 cells. Journal of General Virology 84, 3291-3303 (2003).

69. D. Ferreira, M. Santo, M. Rebello, M. Rebello, Weak bases affect late stages of Mayaro virus replication cycle in vertebrate cells. Journal of medical microbiology 49, 313-318 (2000).

70. S. T. Nawrocki, Y. Han, V. Visconte, J. G. Phillips, B. P. Przychodzen, J. P. Maciejewski, K. R. Kelly, J. S. Carew, Development of ROC-325: A Novel Small Molecule Inhibitor of Autophagy with Promising AntiLeukemic Activity. Blood 128, 525-525 (2016).

71. M. W. Kelly, C. W. Myers, Clomipramine: A Tricyclic Antidepressant Effective in Obsessive Compulsive Disorder. DICP 24, 739-744 (1990).

72. M. Wilson, J. Tripp, in StatPearls. (StatPearls Publishing

Copyright (C) 2020, StatPearls Publishing LLC., Treasure Island (FL), 2020).

73. J. L. Bauman, J. E. Tisdale, Chloroquine and Hydroxychloroquine in the Era of SARS - CoV2: Caution on Their Cardiac Toxicity. Pharmacotherapy: The Journal of Human Pharmacology and Drug Therapy n/a.

74. J. Geleris, Y. Sun, J. Platt, J. Zucker, M. Baldwin, G. Hripcsak, A. Labella, D. Manson, C. Kubin, R. G. Barr, M. E. Sobieszczyk, N. W. Schluger, Observational Study of Hydroxychloroquine in Hospitalized Patients with Covid-19. New England Journal of Medicine, (2020).

75. E. Donohue, A. Tovey, A. W. Vogl, S. Arns, E. Sternberg, R. N. Young, M. Roberge, Inhibition of autophagosome formation by the benzoporphyrin derivative verteporfin. J Biol Chem 286, 7290-7300 (2011).

76. A. E. Balant-Gorgia, M. Gex-Fabry, L. P. Balant, Clinical pharmacokinetics of clomipramine. Clinical pharmacokinetics 20, 447-462 (1991).

77. G. Edwards, A. M. Breckenridge, Clinical pharmacokinetics of anthelmintic drugs. Clinical pharmacokinetics 15, 67-93 (1988).

78. S. Krishna, N. J. White, Pharmacokinetics of quinine, chloroquine and amodiaquine. Clinical implications. Clinical pharmacokinetics 30, 263-299 (1996).

79. J. Ducharme, R. Farinotti, Clinical pharmacokinetics and metabolism of chloroquine. Focus on recent advancements. Clinical pharmacokinetics 31, 257-274 (1996). 
80. A.-L. Laaksonen, V. Koskiahde, K. Juva, Dosage of antimalarial drugs for children with juvenile rheumatoid arthritis and systemic lupus erythematosus: a clinical study with determination of serum concentrations of chloroquine and hydroxychloroquine. Scandinavian journal of rheumatology 3, 103-108 (1974).

81. H. Kollaritsch, J. Karbwang, G. Wiedermann, A. Mikolasek, K. Na-Bangchang, W. H. Wernsdorfer, Mefloquine concentration profiles during prophylactic dose regimens. Wiener klinische Wochenschrift 112, 441-447 (2000).

82. W. Li, M. J. Moore, N. Vasilieva, J. Sui, S. K. Wong, M. A. Berne, M. Somasundaran, J. L. Sullivan, K. Luzuriaga, T. C. Greenough, H. Choe, M. Farzan, Angiotensin-converting enzyme 2 is a functional receptor for the SARS coronavirus. Nature 426, 450-454 (2003).

Ancillary information

\section{- Supporting Information.}

- Fig. S1. Autophagy inhibition assay using LC3B immunostaining in HeLa cells

- Fig. S2. Autophagy inhibition assay using LC3B immunostaining in HEK293T cells

- Fig. S3. Autophagy inhibition assay using LC3B immunostaining in Huh-7.5 cells

- Fig. S4. Autophagy inhibition assay using LysoTracker Deep Red staining in HeLa cells

- Fig. S5. Autophagy inhibition assay using LysoTracker Deep Red staining in HEK293T cells

- Fig. S6. Autophagy inhibition assay using LysoTracker Deep Red staining in Huh-7.5 cells

- Corresponding Author Information:

○ Kirill Gorshkov - kirill.gorshkov@nih.gov

○ Wei Zheng - wzheng@ mail.nih.gov

- Author Contributions:

- Experimental - KG, CC, RB, LR, MX, MP

- Data Analysis - KG, BN

- Compound Management \& Selection - KG, XH, PS, ZI

- Manuscript Conception - KG, CC, WZheng

- Manuscript Writing - KG, CC, KS, WH, WZheng

- Preparation of Figures - KG, CC, WZhu

- Critical Manuscript Editing and Discussion- KG, MP, CC, WZheng, AS, MH, MS, DL

- Laboratory Automation - CK-T, SM

- Acknowledgment:

- We thank Richard Eastman (NCATS) and Sara McKellip (SRI) for assistance with acoustic dispensing support and compound management. We thank the laboratory of Dr. Hengli Tang for providing the Huh-7.5 cells. 
- Abbreviations Used:

- SARS-CoV-2 - Severe acute respiratory syndrome coronavirus 2

- COVID-19 - coronavirus disease that was discovered in 2019

- $\mathrm{CQ}$ - chlorquine

- HCQ - hydroxychloroquine

- LC3B - microtubule-associated proteins 1B light chains 3B

- CPE - cytopathic effect

- SI - selectivity index

- TOX - toxicity measurement for CC50 calculation

- MOI - multiplicity of infection

\section{Supplementary Materials:}

Fig. S1. Autophagy inhibition assay using LC3B immunostaining in HeLa cells

Fig. S2. Autophagy inhibition assay using LC3B immunostaining in HEK293T cells

Fig. S3. Autophagy inhibition assay using LC3B immunostaining in Huh-7.5 cells

Fig. S4. Autophagy inhibition assay using LysoTracker Deep Red staining in HeLa cells

Fig. S5. Autophagy inhibition assay using LysoTracker Deep Red staining in HEK293T cells

Fig. S6. Autophagy inhibition assay using LysoTracker Deep Red staining in Huh-7.5 cells 


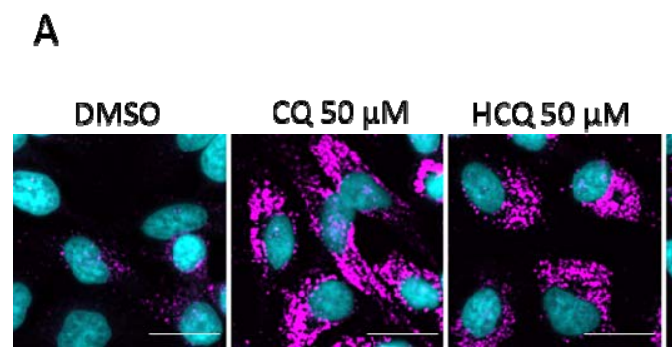

Hoechst 33342 Rabbit anti-LC3B

\section{Clomipramine Mefloquine \\ $50 \mu \mathrm{M}$}

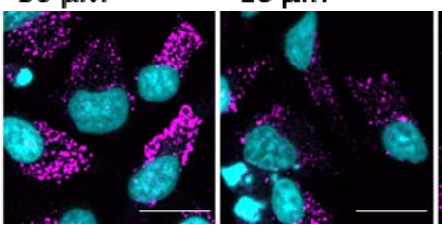

ROC-325

$12 \mu \mathrm{M}$

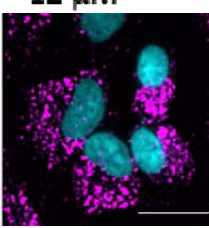

Scale bar, $25 \mu \mathrm{m}$

B
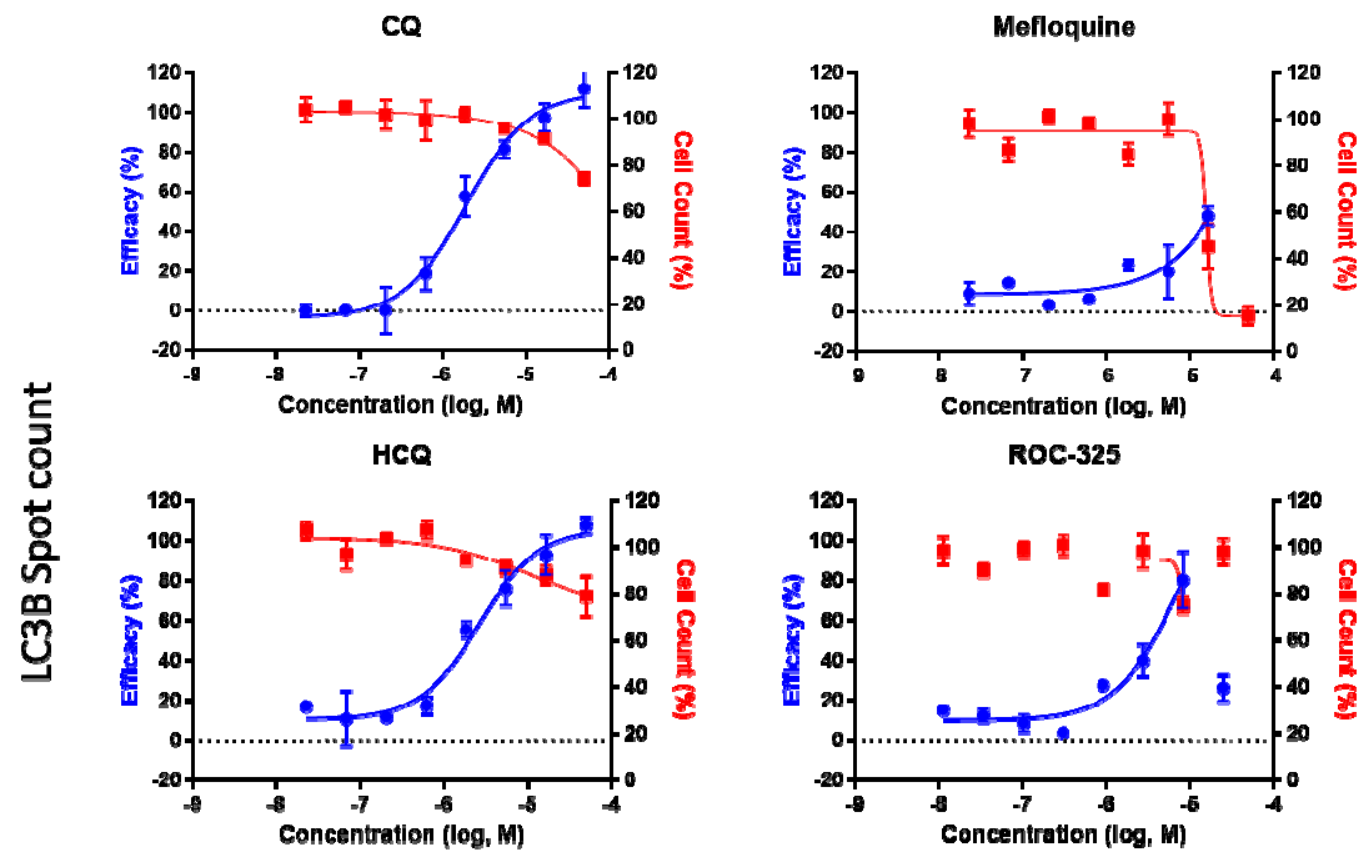

ROC-325

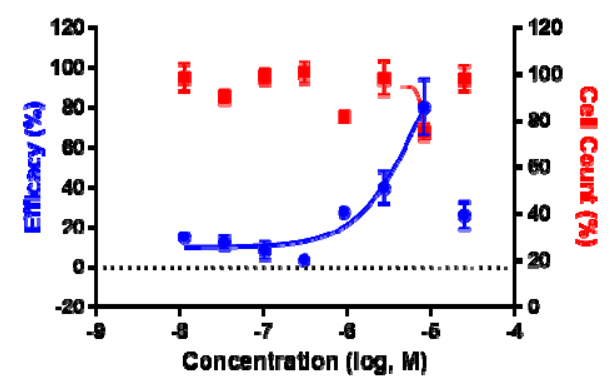

Clomipramine
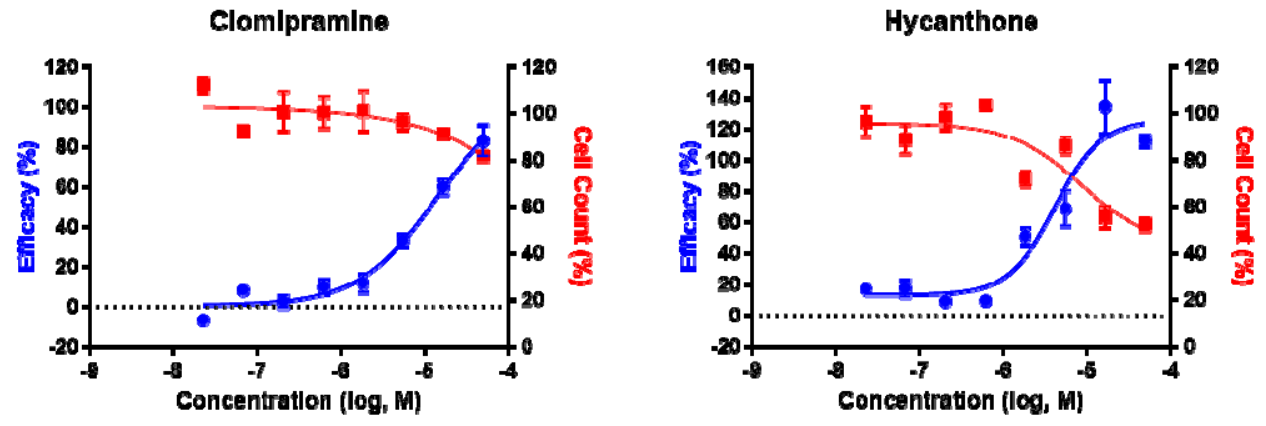

Fig. S1. Autophagy inhibition assay using LC3B immunostaining in HeLa cells. (A) Image montage of DMSO, CQ, HCQ, clomipramine, mefloquine, ROC-325, and hycanthone stained with Hoechst 33342 (cyan) and LC3B (magenta). CQ and HCQ images taken from wells in positive control column 2. Scale bar, $25 \mu \mathrm{m}$. (B) 8 point 1:3 dilution concentration-response 
bioRxiv preprint doi: https://doi.org/10.1101/2020.05.16.091520; this version posted May 28, 2020. The copyright holder for this preprint (which

was not certified by peer review) is the author/funder, who has granted bioRxiv a license to display the preprint in perpetuity. It is made available under aCC-BY-NC-ND 4.0 International license.

curves starting at $50 \mu \mathrm{M}$ down to $0.023 \mu \mathrm{M}$ for compounds in A. Blue curve indicates Efficacy, red curve indicates Cell Counts. Efficacy data normalized to DMSO (0\%) and CQ (100\%). Cell count data normalized to DMSO (100\%) and 0 (no cells $0 \%$ ). Error bars indicate SD. N = 3 intraplate replicates. Curves generated using non-linear regression. 


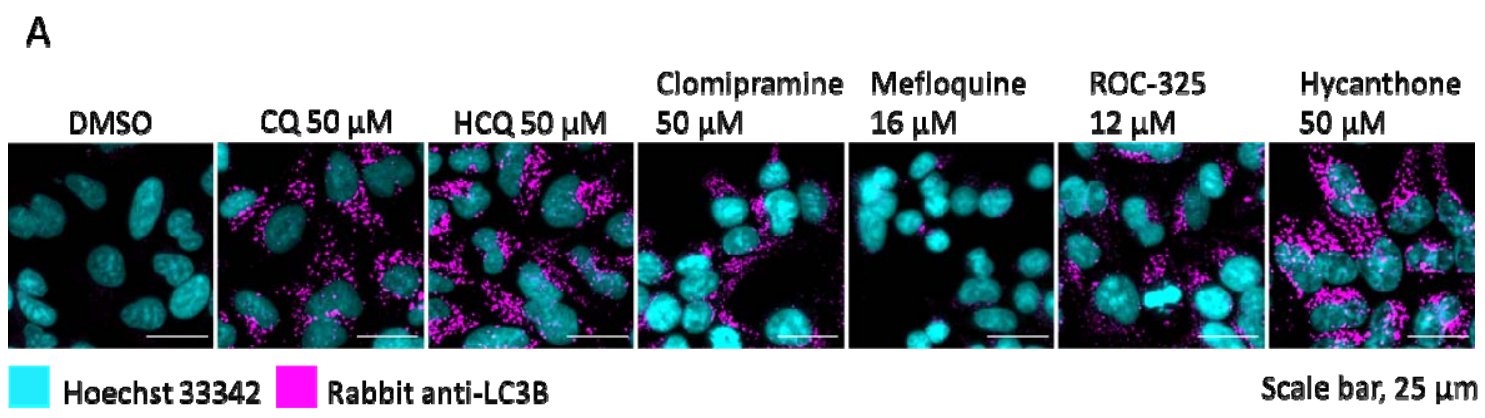

B

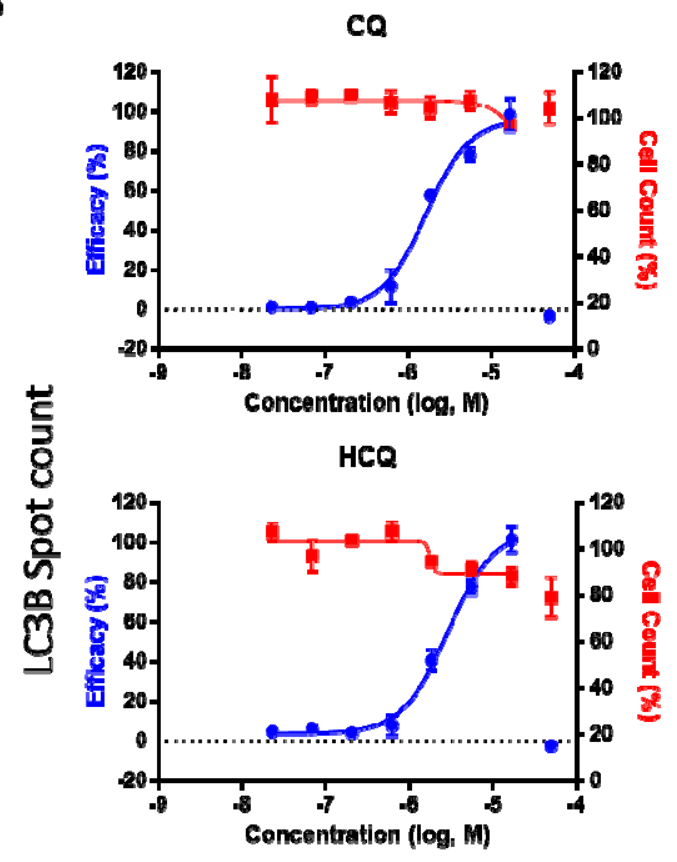

Clomipramino

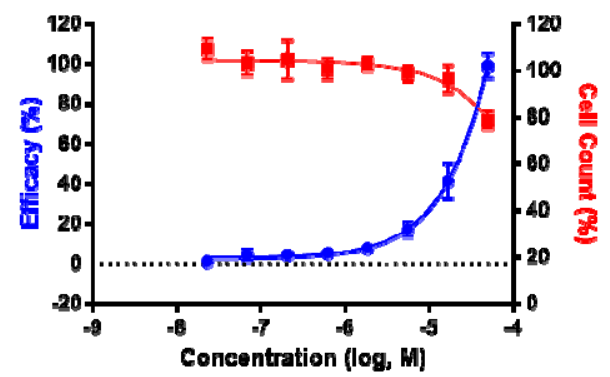

Mefloquine
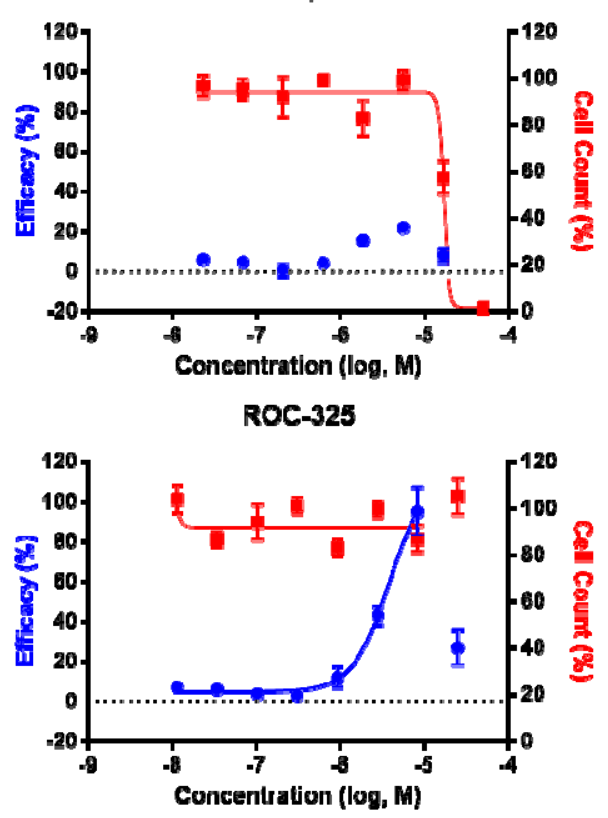

Hycenthono

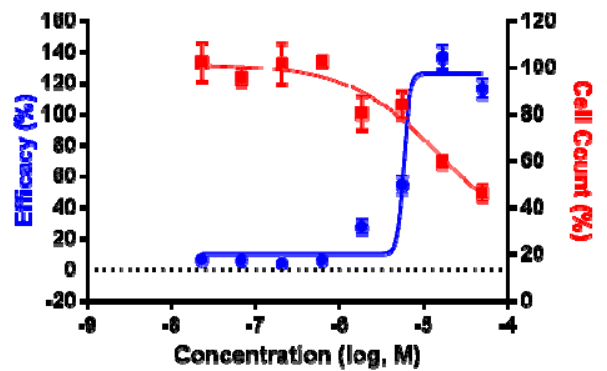

Fig. S2. Autophagy inhibition assay using LC3B immunostaining in HEK293T cells. A) Image montage of DMSO, CQ, HCQ, clomipramine, mefloquine, ROC-325, and hycanthone stained with Hoechst 33342 (cyan) and LC3B (magenta). CQ and HCQ images taken from wells in positive control column 2. Scale bar, $25 \mu \mathrm{m}$. (B) 8 point 1:3 dilution concentration-response 
bioRxiv preprint doi: https://doi.org/10.1101/2020.05.16.091520; this version posted May 28, 2020. The copyright holder for this preprint (which

was not certified by peer review) is the author/funder, who has granted bioRxiv a license to display the preprint in perpetuity. It is made available under aCC-BY-NC-ND 4.0 International license.

curves starting at $50 \mu \mathrm{M}$ down to $0.023 \mu \mathrm{M}$ for compounds in A. Blue curve indicates Efficacy, red curve indicates Cell Counts. Efficacy data normalized to DMSO (0\%) and CQ (100\%). Cell count data normalized to DMSO (100\%) and 0 (no cells $0 \%$ ). Error bars indicate SD. N = 3 intraplate replicates. Curves generated using non-linear regression. 

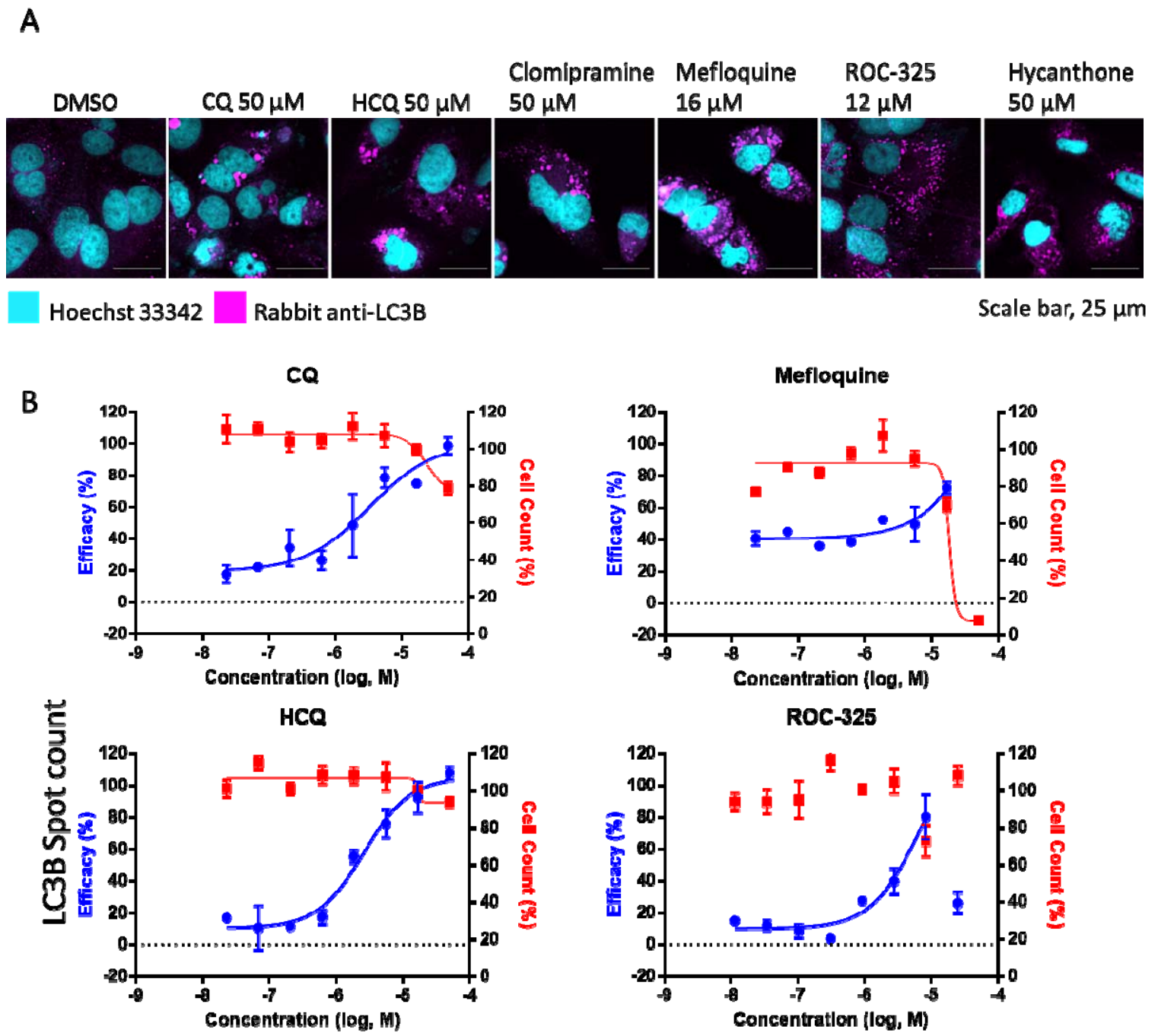

ROC-325

Clomipramine
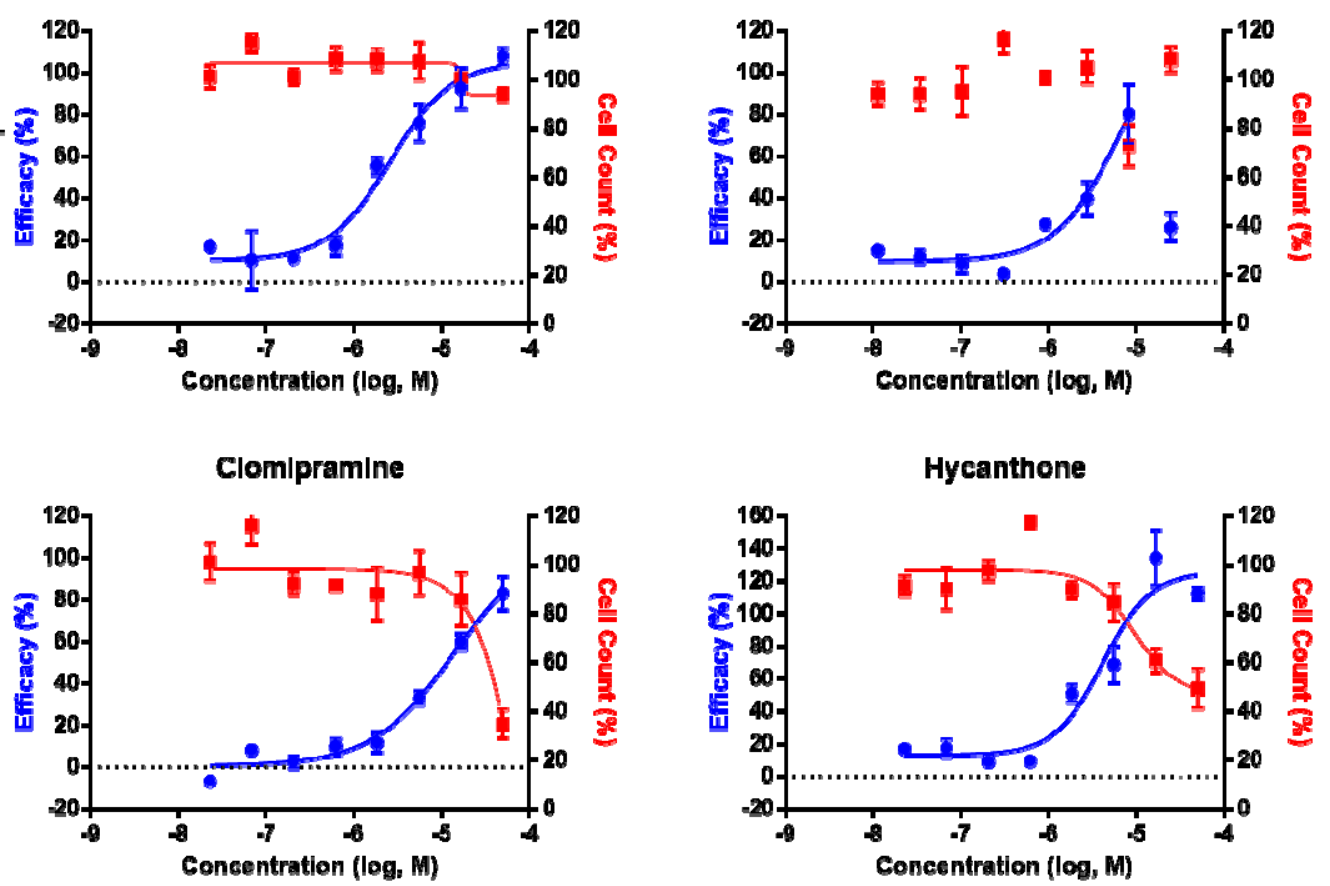

Hycanthone

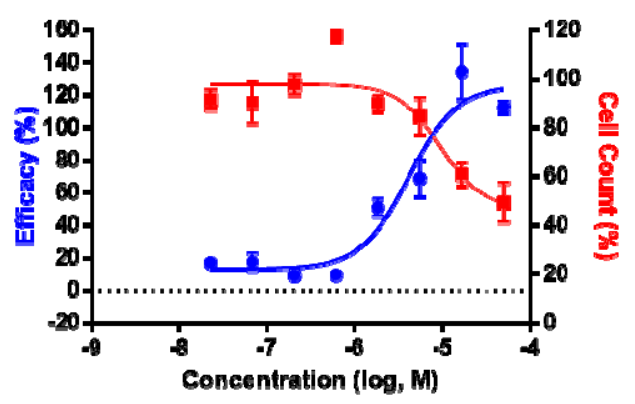

Fig. S3. Autophagy inhibition assay using LC3B immunostaining in Huh-7.5 cells. (A) Image montage of DMSO, CQ, HCQ, clomipramine, mefloquine, ROC-325, and hycanthone stained with Hoechst 33342 (cyan) and LC3B (magenta). CQ and HCQ images taken from wells in positive control column 2. Scale bar, $25 \mu \mathrm{m}$. (B) 8 point 1:3 dilution concentration-response 
bioRxiv preprint doi: https://doi.org/10.1101/2020.05.16.091520; this version posted May 28, 2020. The copyright holder for this preprint (which

was not certified by peer review) is the author/funder, who has granted bioRxiv a license to display the preprint in perpetuity. It is made available under aCC-BY-NC-ND 4.0 International license.

curves starting at $50 \mu \mathrm{M}$ down to $0.023 \mu \mathrm{M}$ for compounds in A. Blue curve indicates Efficacy, red curve indicates Cell Counts. Efficacy data normalized to DMSO (0\%) and CQ (100\%). Cell count data normalized to DMSO (100\%) and 0 (no cells $0 \%$ ). Error bars indicate SD. N = 3 intraplate replicates. Curves generated using non-linear regression. 


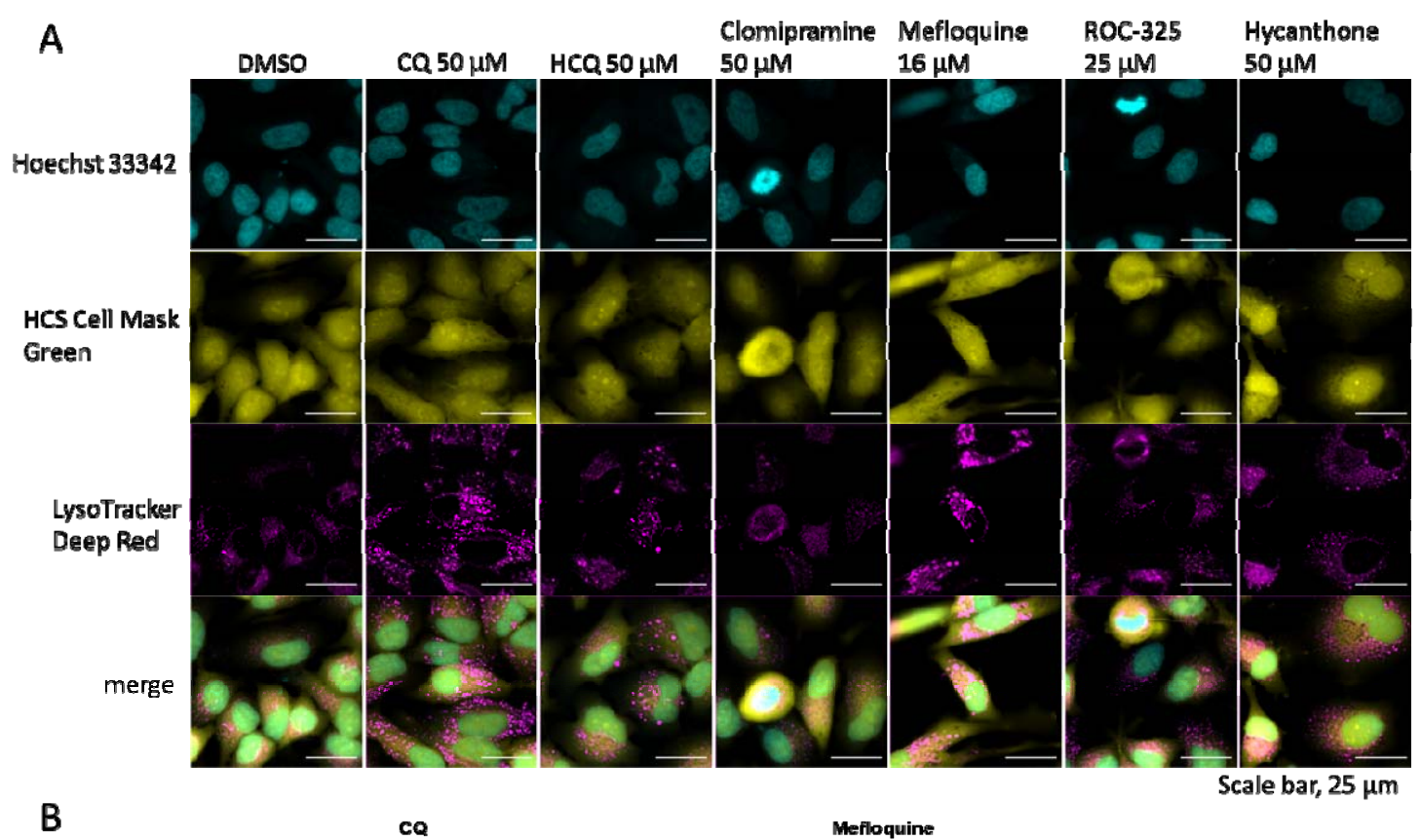

B
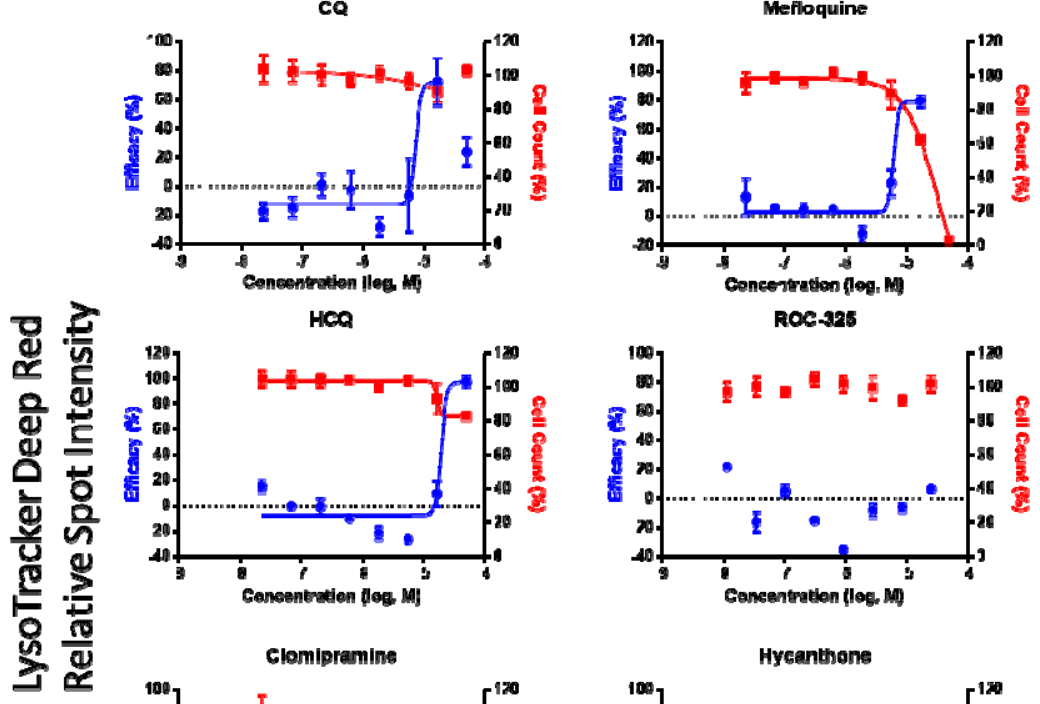

HCQ
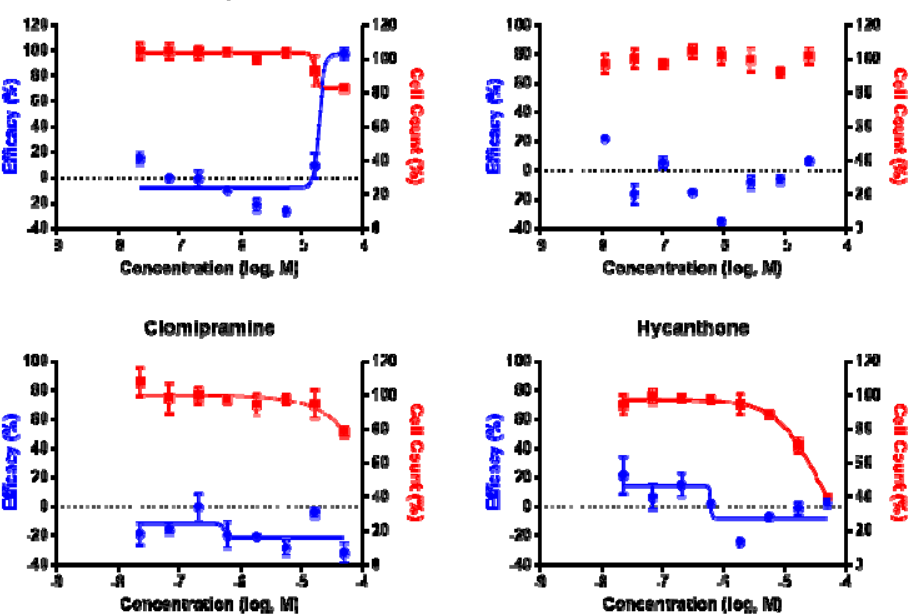

Fig. S4. Autophagy inhibition assay using LysoTracker Deep Red staining in HeLa cells. (A) Image montage of DMSO, CQ, HCQ, clomipramine, mefloquine, ROC-325, and hycanthone stained with Hoechst 33342 (cyan), HCS Cell Mask Green (yellow), and LysoTracker Deep Red (magenta). CQ and HCQ images taken from wells in positive control column 2. Scale bar, 25 
bioRxiv preprint doi: https://doi.org/10.1101/2020.05.16.091520; this version posted May 28, 2020. The copyright holder for this preprint (which

was not certified by peer review) is the author/funder, who has granted bioRxiv a license to display the preprint in perpetuity. It is made available under aCC-BY-NC-ND 4.0 International license.

$\mu \mathrm{m}$. (B) 8 point 1:3 dilution concentration-response curves starting at $50 \mu \mathrm{M}$ down to $0.023 \mu \mathrm{M}$

for compounds in A. Blue curve indicates Efficacy, red curve indicates Cell Counts. Efficacy data normalized to DMSO (0\%) and CQ (100\%). Cell count data normalized to DMSO (100\%) and 0 (no cells $0 \%$ ). Error bars indicate SD. $\mathrm{N}=3$ intra-plate replicates. Curves generated using non-linear regression. 


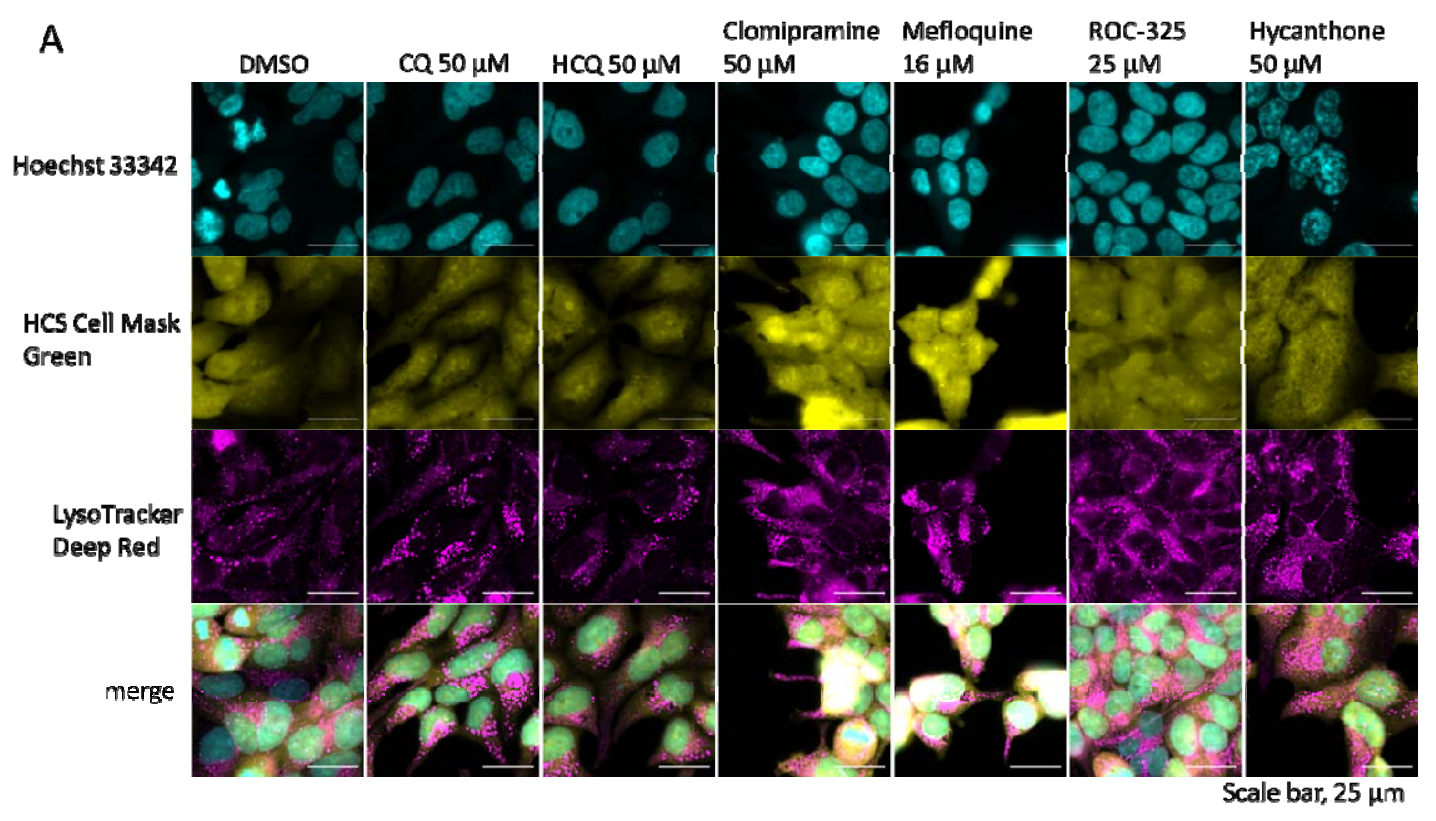

B

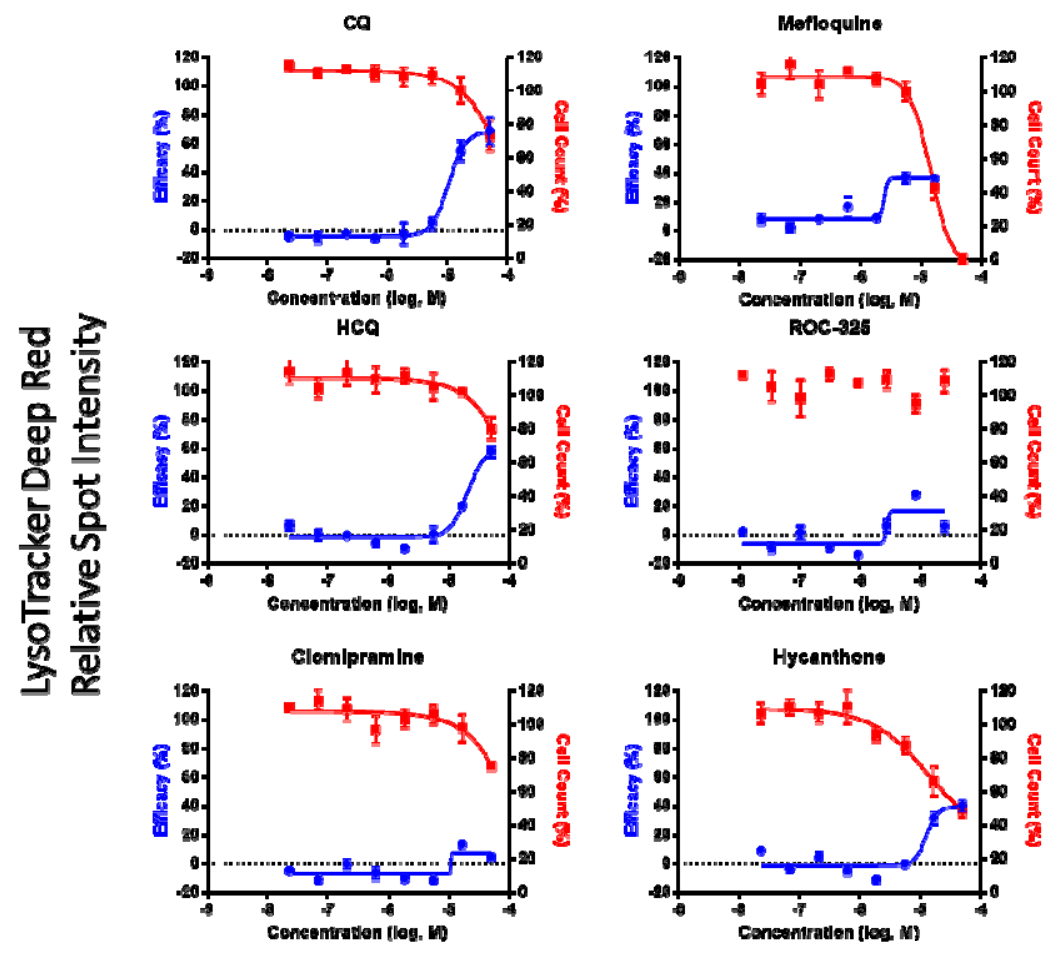

Fig S5. Autophagy inhibition assay using LysoTracker Deep Red staining in HEK293T cells. (A) Image montage of DMSO, CQ, HCQ, clomipramine, mefloquine, ROC-325, and hycanthone stained with Hoechst 33342 (cyan), HCS Cell Mask Green (yellow), and LysoTracker Deep Red (magenta). CQ and HCQ images taken from wells in positive control column 2. Scale bar, 25 $\mu \mathrm{m}$. (B) 8 point 1:3 dilution concentration-response curves starting at $50 \mu \mathrm{M}$ down to $0.023 \mu \mathrm{M}$ 
bioRxiv preprint doi: https://doi.org/10.1101/2020.05.16.091520; this version posted May 28, 2020. The copyright holder for this preprint (which

was not certified by peer review) is the author/funder, who has granted bioRxiv a license to display the preprint in perpetuity. It is made available under aCC-BY-NC-ND 4.0 International license.

for compounds in A. Blue curve indicates Efficacy, red curve indicates Cell Counts. Efficacy data normalized to DMSO (0\%) and CQ (100\%). Cell count data normalized to DMSO (100\%) and 0 (no cells $0 \%$ ). Error bars indicate SD. $\mathrm{N}=3$ intra-plate replicates. Curves generated using non-linear regression. 


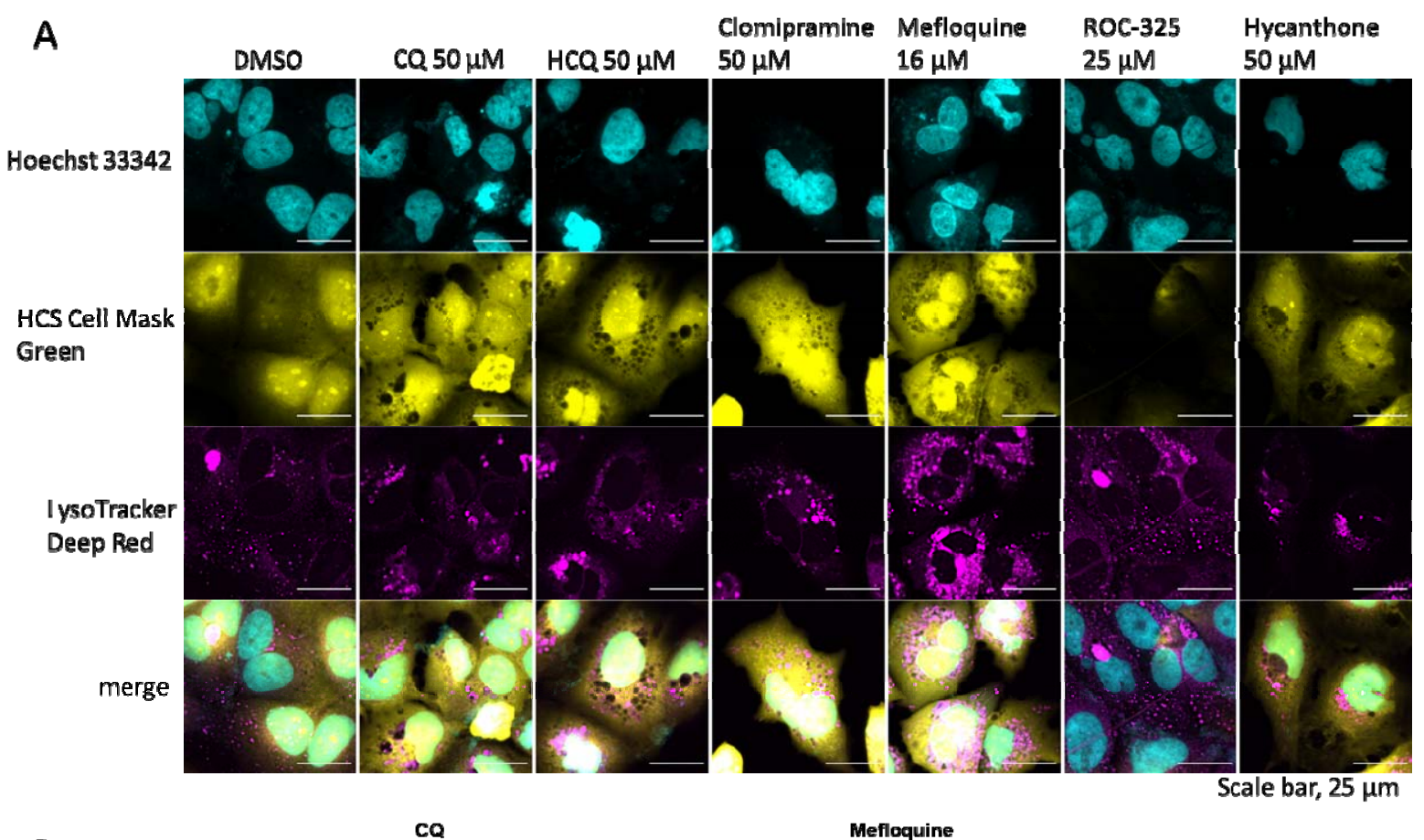

B
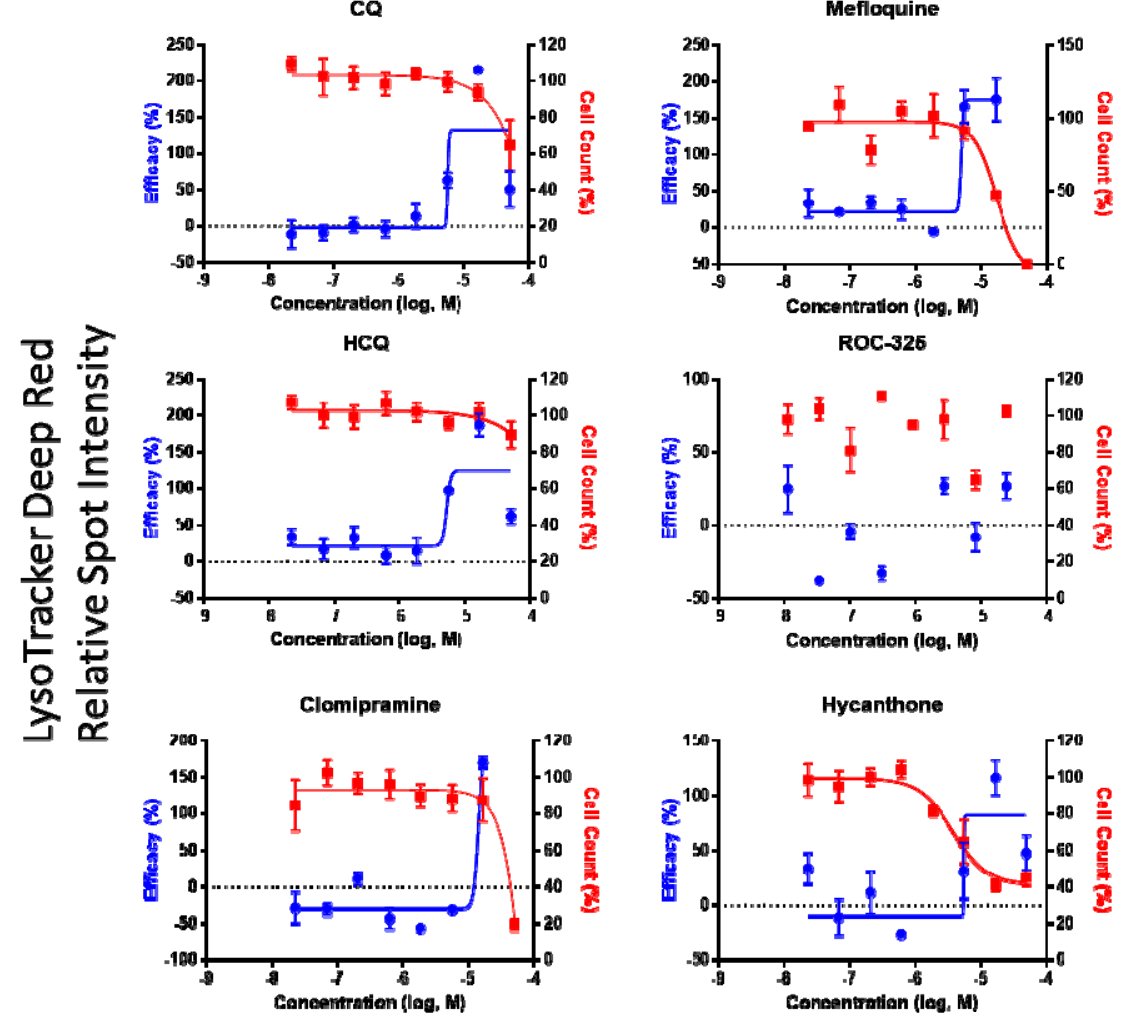

Fig S6. Autophagy inhibition assay using LysoTracker Deep Red staining in Huh-7.5 cells. (A) Image montage of DMSO, CQ, HCQ, clomipramine, mefloquine, ROC-325, and hycanthone stained with Hoechst 33342 (cyan), HCS Cell Mask Green (yellow), and LysoTracker Deep Red 
(magenta). CQ and HCQ images taken from wells in positive control column 2. Scale bar, 25

$\mu \mathrm{m}$. (B) 8 point 1:3 dilution concentration-response curves starting at $50 \mu \mathrm{M}$ down to $0.023 \mu \mathrm{M}$

nM for compounds in A. Blue curve indicates Efficacy, red curve indicates Cell Counts. Efficacy

data normalized to DMSO (0\%) and CQ (100\%). Cell count data normalized to DMSO (100\%)

and 0 (no cells $0 \%$ ). Error bars indicate SD. $\mathrm{N}=3$ intra-plate replicates. Curves generated using non-linear regression. 